Portland State University

PDXScholar

5-4-1989

\title{
Awareness of Biculturalism in Families of Intercultural Marriage
}

Eleesabeth Carol-Therese Vieira

Portland State University

Follow this and additional works at: https://pdxscholar.library.pdx.edu/open_access_etds

Part of the International and Intercultural Communication Commons Let us know how access to this document benefits you.

\section{Recommended Citation}

Vieira, Eleesabeth Carol-Therese, "Awareness of Biculturalism in Families of Intercultural Marriage" (1989). Dissertations and Theses. Paper 3960.

https://doi.org/10.15760/etd.5844

This Thesis is brought to you for free and open access. It has been accepted for inclusion in Dissertations and Theses by an authorized administrator of PDXScholar. Please contact us if we can make this document more accessible: pdxscholar@pdx.edu. 
AN ABSTRACT OF THE THESIS OF Eleesabeth Carol-Therese vieira for the Master of Arts in speech Communication presented May 4,1989 .

Title: Awareness of Biculturalism in Families of Intercultural Marriage.

APPROVED BY MEMBERS OF THE THESIS COMMITTEE:
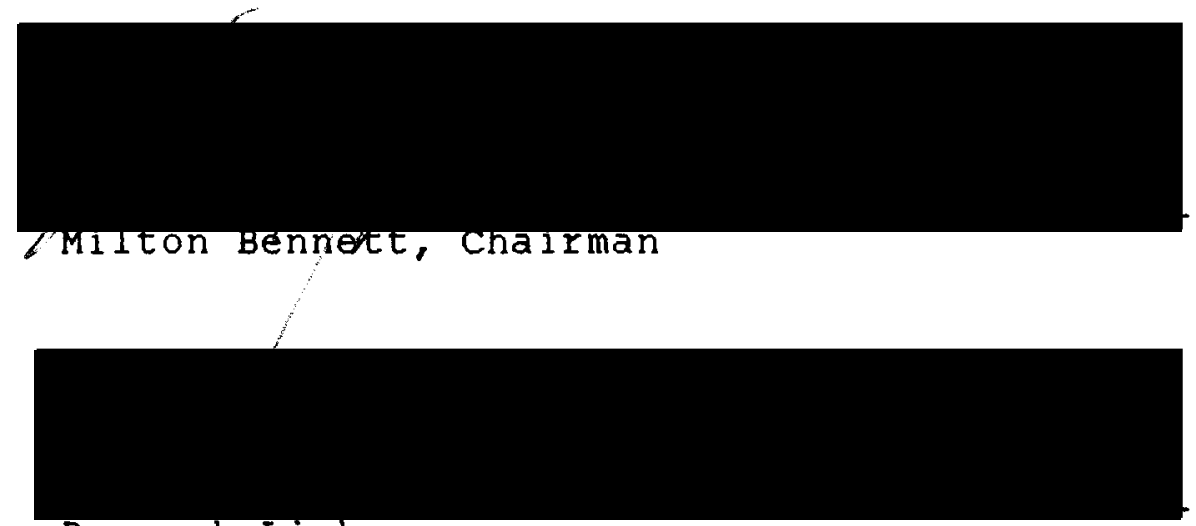

Devorah Lieberman
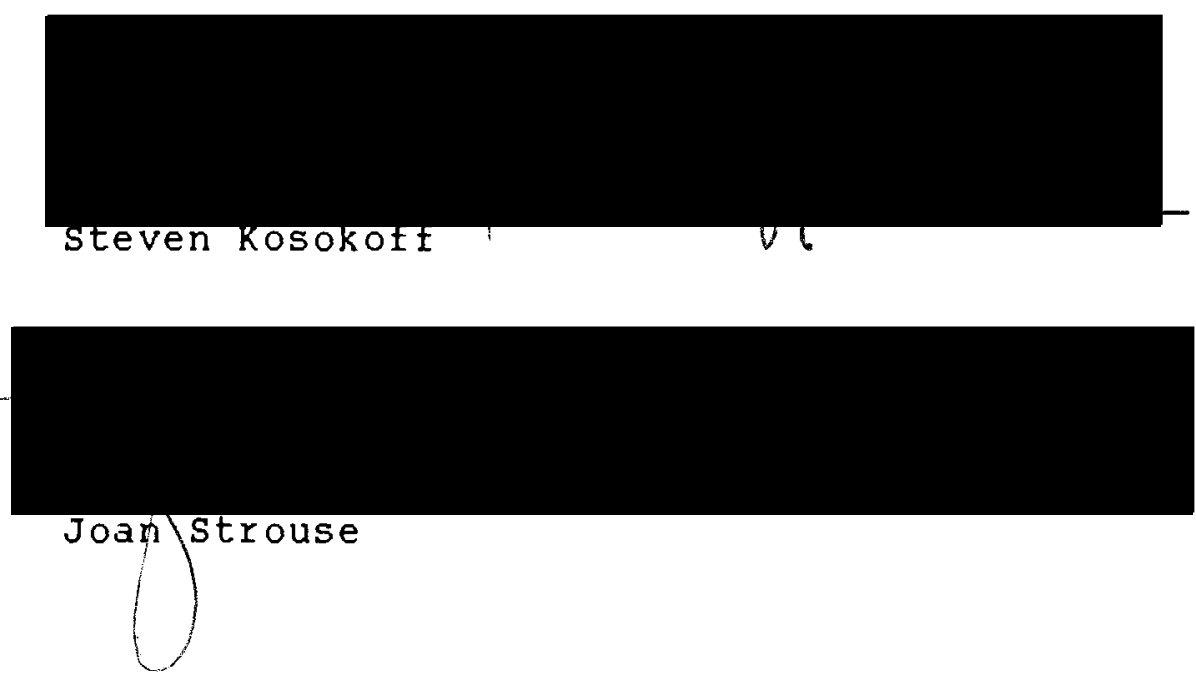

The overall purpose of this preliminary study is to generate more information in the area of intercultural marriage. The specific objectives of the study are to 
explore the extent to which families of intercultural marriage are aware of the issues of biculturalism that are discussed as significant in the literature; the extent to which partners of intercultural marriage discuss these issues with one another or with their children; the extent to which the family members' subjective reports of "awareness" are consistent.

This study utilized a qualitative method of data collection. Information was generated through a review of the literature, the use of preliminary surveys, and followup in-depth interviews.

Based on a review of the literature of intercultural marriages and biculturalism, ten problematic and nine advantageous implications of biculturalism were found. Following a preliminary survey, six themes found prevalent in both the literature review and the surveys were selected for follow-up in the interviews. An additional five new themes were also generated and looked for in the follow-up interviews.

Interviews were conducted with the partners of nine American/Non-American marriages, as well as with seven children of these marriages between the ages of 13 - 19 . Seven of the couples were composed of an American wife and a Non-American husband, and the remaining two of American husbands and Non-American wives.

An analysis of the responses indicated that couples and the children interviewed demonstrated a higher awareness of 
advantageous issues than disadvantageous ones. Parents reported that they seldom discuss cultural differences, or Implications of biculturalism with their children. Furthermore, parents disclosed that they discuss advantageous themes with each other more often than problematic issues. Results also indicated that communication about cultural differences increases as the children grow older.

Although the importance of the role of communication as indicated by the literature was not supported by results from this study, the researcher found a high level of consistency in issues reported by the interview subjects. 


\title{
AWARENESS OF BICULTURALISM IN FAMILIES \\ OF INTERCULTURAL MARRIAGE
}

by

ELEESABETH CAROL-THERESE VIEIRA

A thesis submitted in partial fulflilment of the requirements for the degree of

\author{
MASTERS IN ARTS \\ in \\ SPEECH COMMUNICATION
}

Portland state University

1989 
TO THE OFFICE OF GRADUATE STUDIES:

The members of the committee approve the thesis of Eleesabeth Carol-Therese Vieira presented May 4, 1989.

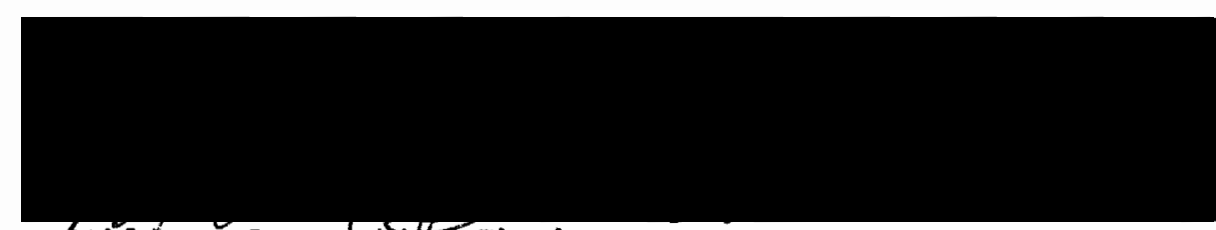

Milton Bennetf Chairman
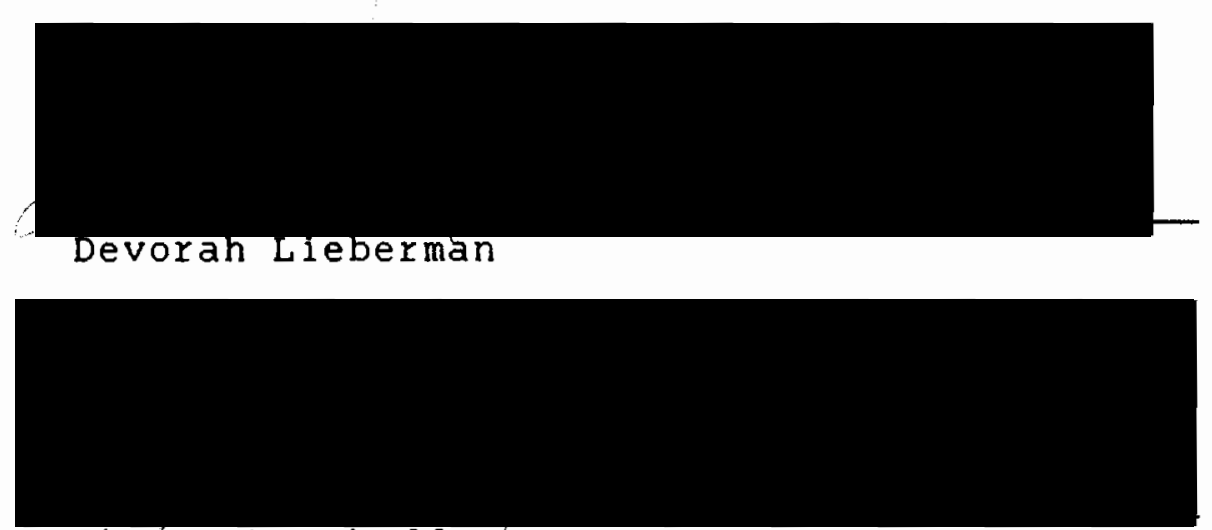

Steven Kosokoft
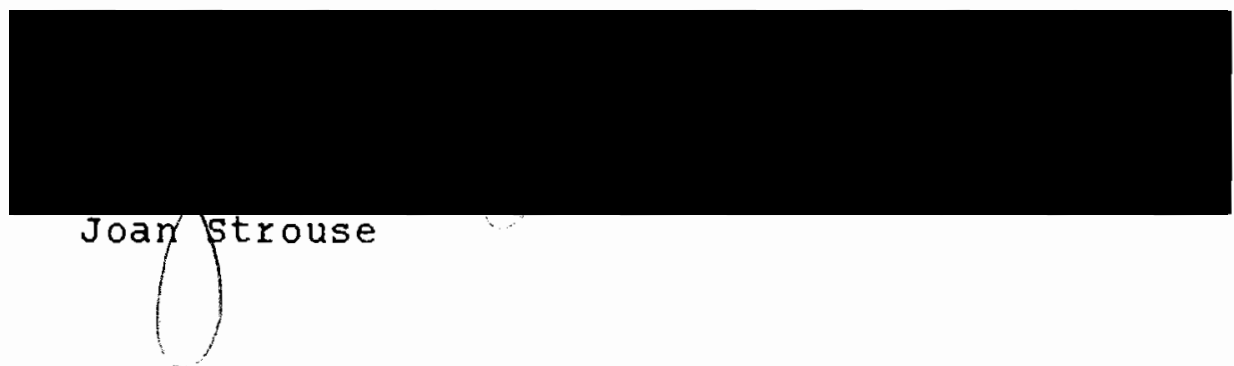

APPROVED :

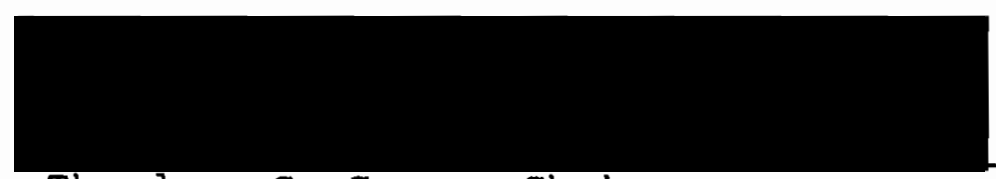

Theodore G. Grove, Chairman

Department of speech Communication

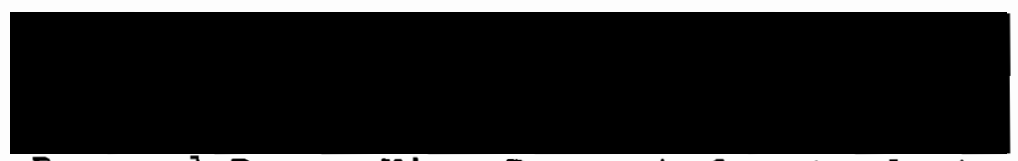

Bernard Ross, Vice Provost for Graduate studies 


\section{ACKNOWLEDGEMENTS}

My personal experlence as a partner of an intercultural marriage inspired me to pursue this topic. Most of all, I want to thank my husband, Jorge, for his patience, encouragement and sense of humor which enabled me to complete this thesis.

I am thankful to Dr. Bennett, Dr. Lleberman and Dr. Kosokoff for their teaching excellence, advice, and support throughout my graduate career.

I am indebted to Anne, Linda and Noriko for enduring an endless array of phone calls, and for their invaluable insight which enabled me to see beyond my brick walls.

Finally, I want to express my thanks to my mother, Judith F. Duncan, who raised me to respect and have confidence in myself. I love you and am forever grateful to you for who I am.

This thesis is dedicated to our newborn son, Luke Bryant Martins Vieira. We ask for your patience as we endeavor to raise you a caring and conscious portugueseAmerican, and a more interculturally sensitive human being. 
TABLE OF CONTENTS

PAGE

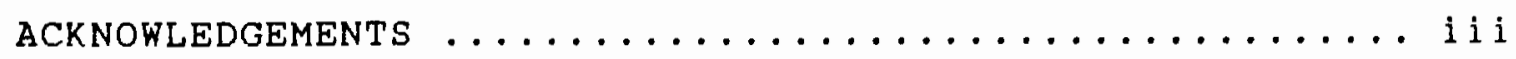

LIST OF TABLES $\ldots \ldots \ldots \ldots \ldots \ldots \ldots \ldots \ldots \ldots \ldots \ldots \ldots$

\section{CHAPTER}

I

INTRODUCTION $\ldots \ldots \ldots \ldots \ldots \ldots \ldots \ldots \ldots \ldots \ldots \ldots$

overview $\ldots \ldots \ldots \ldots \ldots \ldots \ldots \ldots \ldots \ldots \ldots$

Purposes of This study $\ldots \ldots \ldots \ldots \ldots \ldots$

Justification and significance........ 2

Operational Definitions ........... 4

I I LITERATURE REVIEW $\ldots \ldots \ldots \ldots \ldots \ldots \ldots \ldots \ldots$

Overview $\ldots \ldots \ldots \ldots \ldots \ldots \ldots \ldots \ldots \ldots \ldots \ldots$

Problematic Implications of Biculturalism 11

Advantageous Implications of Biculturalism 17

I I METHODS $\ldots \ldots \ldots \ldots \ldots \ldots \ldots \ldots \ldots \ldots \ldots \ldots$

General Methodology $\ldots \ldots \ldots \ldots \ldots \ldots \ldots 21$

Subject Selection and Population ...... 23

The Interview Procedure $\ldots \ldots \ldots \ldots \ldots 26$

The Interview schedules ........... 29

Data Analysis Procedures ........... 34

IV RESULTS AND DISCUSSION $\ldots \ldots \ldots \ldots \ldots \ldots \ldots$

Preliminary survey Results ........ 37

Preliminary survey Discussion ........ 41 
Parents' Interview Results .......... 44

Parents' Interview Discussion ....... 56

Children's Interview Results ......... 62

Children's Interview Discussion ....... 68

$V$ SUMMARY AND CONCLUSION, LIMITATIONS, AND

SUGGESTIONS FOR FURTHER RESEARCH $\ldots \ldots \ldots 75$

Summary and Conclusion .......... 75

Limitations $\ldots \ldots \ldots \ldots \ldots \ldots \ldots$

Suggestions for Further Research ...... 83

REFERENCES

APPENDICES

A PRELIMINARY THEMATIC ANALYSIS OF THE LITERATURE 89

B PRELIMINARY SURVEY $\ldots \ldots \ldots \ldots \ldots \ldots \ldots \ldots$

C THEMATIC ANALYis OF THE PRELIMINARY SURVEY $\ldots 92$

D THEMES FROM THE LITERATURE AND PRELIMINARY $\ldots 93$ SURVEYS

E PAREnts' interview SCHEdULE $\ldots \ldots \ldots \ldots \ldots \ldots$

F CHILdREn's inteview SChEdULE $\ldots \ldots \ldots \ldots$

G INFORMATION ON PARTICIPANTS .......... 103

H INFORMATION ON CHILDREN PARTICIPANTS $\ldots \ldots \ldots 106$ 


\section{LIST OF TABLES}

TABLE

PAGE

I Overall Response Means of the Preliminary survey

I Parents' Perceptions of the Awareness of Issues of Biculturalism by Their Children

II Parents' Perceptions of the Importance of

Their Children's Awareness of Difference

IV Parents' Perceptions of the Importance of

Discussion About Cultural Difference 


\section{CHAPTER I}

\section{INTRODUCTI ON}

\section{OVERVIEW}

This study is a preliminary exploration of awareness and communicative behaviors of families of intercultural marriage, related to biculturalism. It looks at the extent to which dual-socialized children report awareness of the issues reported as inherent in a bicultural upbringing, and the extent to which couples of intercultural marriage report an awareness of these issues. The congruence between implications discussed in the literature and subjective reports of awareness and communicative behaviors of members of intercultural families is explored.

\section{PURPOSES OF THIS STUDY}

The purpose of this study is to generate more information in the area of Intercultural Marriage. Primarily, it seeks to determine whether families of intercultural marriage are aware of potential problems and advantages inherent in a bicultural upbringing as discussed in the literature. In other words, are the implications of socialization involving exposure to two cultural frames of reference reported as important issues by families of 
intercultural marrlage? This study will also examine whether the subjective reports of awareness by children of intercultural marriage are consistent with those of the parents.

These purposes will be explicated as the following research questions are pursued:

1. To what extent are couples of an intercultural marriage aware of the issues of biculturalism that are discussed in the literature?

2. To what extent do partners of an intercultural marriage discuss these issues with one another, or with their children?

3. To what extent are children of intercultural marriages aware of the issues that are discussed as significant in the literature?

4. To what extent are the children's subjective reports of awareness consistent with reports of awareness by parents?

\section{JUSTIFICATION AND SIGNIFICANCE}

Interaction among people of different cultures is not new. In our time, more people are experiencing crosscultural contact due to economic development and technological advances. In fact, the number of people traveling and living in cultures other than their own is steadily increasing, generating more contacts among diverse people, and creating more opportunities for marriage outside 
a specific cultural group. The number of marriages among members of different cultural groups has grown rapidly in recent years (Erzen-Toyoshima, 1986). Although an increasing body of literature on intercultural marriage is available, little has been written on the experience of the offspring of intercultural marriage. The literature available focuses mainly on the problematic issues children of intercultural marriage experience. Discussion regarding positive aspects of socialization in families of intercultural marriage is fairly new. Lambert (1967) suggests that bicultural bilinguals are:

...the ones most likely to work out a new nonethnocentric mode of social intercourse which could be of universal significance. (p. 100)

Ten years later, Tseng, McDermott, and Maretzki (1977) stated that intercultural marriage has produced a type of "third culture" of children who have learned to deal with cultural difference, and that as these marriages increase, so does this 'third culture' population. There is, however, a paucity of empirical information addressing how children respond to the simultaneous socializing influences experienced in a bicultural upbringing (Harper, 1986). whether children of intercultural marriages appear to experience the advantages of biculturalism has not yet been documented (Johnson and Nagosh1, 1986), nor does the literature discuss, in any depth, the awareness families of intercultural marriage demonstrate regarding the issues discussed as significant in the literature. And, 
furthermore, nothing has been written speciflcally focusing on the role of communication within these families (Rohrlich, 1988).

The impact intercultural marriage has on children in their formative years could directly affect their ability to be culturally sensitive to difference, and to be consciously aware of how these differences are culturally relative. These two concepts are the main assumptions of the current intercultural communication difference-based approach, which stresses the assumption of difference and cultural relativity, and are of great significance to scholars of intercultural communication.

Findings from this study can benefit family members of intercultural marriages, those considering marrying and raising a family with someone from a cultural background different from their own, and scholars of intercultural communication.

\section{OPERATIONAL DEFINITIONS}

\section{Intercultural Marriage}

There are several terms used interchangeably in the literature when discussing intercultural marriages. Rohrlich (1988) suggests that the term 'intercultural' lacks specificity when focusing on the cultural aspects. She introduces the term 'dual-culture' marriage, defining it as "...the marriage between persons who do not share the same 
culture (perceptions, value orientations, and customs)" (pp. 35-36). Ho (1984) uses the term 'international marriage' to refer to marriage between people of different ethnic and/or cultural backgrounds. Gordon (1964) uses the term 'intermarriage' to refer to interfaith, interracial, and interethnic marriage. And finally, Tseng et. al. (1977) discuss intercultural marriage as marriage between partners of different cultural backgrounds. For the purposes of this study, the term intercultural marriage will be defined as marriage between people of different national, cultural and linguistic backgrounds, involving one U.S. and one non U.S. partner.

\section{Biculturalism}

The children of intercultural marriages are often referred to as "bicultural". Stonequist (1935) was one of the first to use the term 'bicultural'. His use of the term refers to situations which involved people from two cultures. Over the years, this term has been applied to children raised in settings involving primary socialization in two cultures, or the exposure to two cultures over extended periods of time. According to Paulston (1978), "..there is nothing written on biculturalism" (p. 369). Although dictionary definitions exist, there seems to be no specific definition upon which the literature agrees. Ikeda (1985) defines biculturality as being in the middle of two cultures. Ikeda follows Lum's (1982) discussion of biculturalism as the development of "a dual culture 
personality that is constantly shifting and changing" ( $p$. 22). According to Ikeda, the bicultural person's behavior would be a mixture of both cultures, and he would have the ability to switch back and forth between them, behaving appropriately in each culture. Lum refers to this idea as cultural pluralism. The thoughts and actions of a culturally pluralistic person, in Lum's view, reflect both cultures. Hoopes (1981) defines biculturality as the learning of a second set of categories of meaning by which the person is able to judge his experience. His differentiation resembles Ikeda's definition of biculturalism.

A bicultural person, according to Hoopes, operates from a dual-cultural personality, whereas a multicultural person is able to adapt successfully to any new culture through the application of intercultural communication skills. As I pursue this study, biculturalism will be conceptually defined as the ability to move in and out of two cultures, with adaptation to and acceptance by both cultures. This definition is congruent with the following statement by Harper (1986):

Bicultural people are those individuals who have been socialized within two cultural domains, and exposed to the values, beliefs, esthetic standards, linguistic expressions, patterns of thinking, behavioral norms, and styles of communication espoused by the members of two cultures. (p. 9) 


\title{
CHAPTER II
}

\section{LITERATURE REVIEW}

\author{
OVERVIEW
}

The following overview of the literature concerning families of intercultural marriage and biculturalism focuses on the problems and advantages inherent in a bicultural upbringing and the communicative behaviors of families of intercultural marriage.

In Hawai alone, approximately 50 percent of all marriages are intercultural (Tseng et. al., 1977). It has been estimated that approximately one out of three marriages in the United states is an intercultural marriage (Ho, $1984)$.

In any marriage, the relationship is highly influenced by communication between the partners (Erzen-Toyoshima, 1986). In an intercultural marriage, significant cultural differences may influence the communication process, creating a need for the awareness of difference by each partner. Barna (1988) discusses the tendency for people to believe that "... deep down we're all alike..." (p. 322). Although most people recognize that those from different cultures speak different languages, have different customs and holidays, and even eat different foods, those who are 
willing to place themselves in situations where they actually experience these differences are few. Even fewer are those who accept, adapt to and or practice customs or behaviors other than their own, thus reinforcing the naive assumption of similarity addressed by Barna. The concept of cultural difference is of extreme importance. Condon and Yousef (1979) suggest that all communication behaviors stem from our primary culture, therefore, when people from two different cultures interact, awareness of these significant cultural differences is extremely important and beneficial. They also point out that culture and communication must be considered simultaneously. As further support of this, Porter and Samovar (1985) mention that:

Culture and communication are inseparable because culture not only dictates who talks with whom, about what, and how the communication proceeds, it also helps to determine ... the meanings they have for messages.... In fact, our entire repertory of communicative behaviors is dependent largely on the culture in which we have been raised. (p. 20)

If the couple is not aware that different perspectives, behaviors and expectations are based on cultural differences, communlcation barriers can arise. These couples need to have an awareness of the cultural differences that exist, and of the implications of such difference for their children. Bodger (1984) states:

Even when the initial obstacles of cultural difference are overcome ... another stress point can occur when children are born.... strong feelings can come into play ... as long as a "tug of war" doesn't develop between parents. Children of cross-cultural marriage 
can reap the benefits ... a more balanced outlook on life (p. 319).

Harper (1986) states that there is a different pattern of development among children who are raised in intercultural environments:

A primary socialization process involving exposure to more than two international environments with distinct cultural perspectives and separate world view may create a psychocultural development pattern that is recognizably distinct from the development pattern of individuals socialized within a single culture. (p. 3 )

According to Tseng et. al. (1977) differences in chlldrearing patterns, ldeas and philosophies combined with the increase in intercultural marriage leads us to question childrearing consequences of intercultural marriage.

The concept of cultural difference is one of the most important factors in the field of intercultural communication. Intercultural communication 1s, among other things, an approach which introduces concepts and develops skills in students, attempting to reach the ultimate goal of increased intercultural sensitivity.

Bennett (1986) presents an entire developmental model on intercultural sensitivity based on the recognition, acceptance and adaptation of difference in overcoming ethnocentrism. He states:

The Importance of "difference" is so widely accepted in the field of intercultural communication that it is sometimes overlooked as the major factor in a learner's successful acquisition of the intercultural perspective. (p. 30$)$ 
Difference is the key concept noted in Bennett's model of intercultural sensitivity. Bennett deals with this issue through developing an individual's abllity to move from an ethnocentric stance, where one is less able to deal effectively with difference, to stages of increased sensitivity which he refers to as "ethnorelativism." Ethnorelativism involves an increasing awareness and implies that choices and decisions made are not based on absolutist principles. The concept of cultural difference is seen as Inevitable, nonthreatening, and enjoyable (Bennett, 1986).

Bennett's developmental model of intercultural sensitivity is the only one which deals specifically with the developmental experience. His model allows diagnosis of an individual's developmental state of intercultural sensitivity in order to "choose appropriate concepts and techniques to begin an educational effort" (p. 31). However, this educational effort concentrates on those who have already been soclalized. Bennett focuses on the development of students. He claims such a model "should enable learners to comprehend and experience difference..." (p. 28). Although Bennett deals mainly with the development of older students, his model can be adapted and used educationally with children at younger ages.

Kant (1985) discusses Erikson's contention that good adjustment in adulthood comes only after more important matters have been put in proper perspective at a younger age. Therefore, adults will have more success at being 
interculturally sensitive if these issues have been dealt with in childhood or adolescence. In a family of intercultural marriage children can experience such difference on a daily basis. The environment intercultural educators try to establish for their students is, for these children, everyday life. However, whether the parents demonstrate an awareness of, or take advantage of this is unknown.

Although an increasing body of material on intercultural marriage is available, a review of the literature yields a paucity of information regarding the developmental process of a dual-cultural upbringing, or on the positive impact these marriages have on children. The literature tends to be directed towards problems children of intercultural marriage encounter, focusing mainly on the psychological and emotional problems they are likely to experience (Bossard and Boll, 1957; Gordon, 1964; and Tseng et. al., 1977).

In the following sections, the problematic and advantageous implications of biculturalism are summarized based on a qualitative analysis of the literature.

\section{PROBLEMATIC IMPLICATIONS OF BICULTURALISM}

Bossard and Boll (1957) discuss the crises which can arise when couples who are interculturally married experience differences in their values, ideas and philosophies as they relate to childrearing. Each parent 
represents a different way of thinking and behaving. These differences can lead to serious questioning regarding which culture is to be transmitted.

Bossard and Boll (1957) speculate that people in intermarriages realize their children will either encounter or cause problems. Differences in values and/or the roles to be played by the chlldren may arlse, generating difficulties for the child. The child may suffer what Tseng et. al. (1977) term "culture-conflict", which can deter healthy adjustment of a child. This can also lead to conflict within the family. When two different cultures are presented, the child could develop a dual pattern of identification, leading to contradictory sentiments, or more specifically, feelings of divided loyalty. In such a case, the external conflict between the parents can continue within the child's mind, possibly experiencing a compelling need to choose between the two. The child may internalize conflicting roles and attitudes displayed by the parents. Another possibility is the case where the parents display a "hands-off" attitude, refusing to impose values on their children, allowing them to develop themselves. In this case, the children are left with no guidance or role model. The factor of encountered differences in communication between partners of an intercultural marriage is extremely important in the subjective experience of the child's upbringing. Condon and Yousef (1979) state: 
behavior according to the norms of our culture. (p. 34)

Familial interaction is the first contact children have. Children discover and define themselves through the interaction process (U.S. Commission, 1979). Berger and Luckmann (1967) discuss primary socialization as the process imposed during childhood by significant others. Primary socialization prepares children to become members of society. The child will identify and internalize the roles and attitudes of significant others. If both parents are not totally accepting of the child, it could have a detrimental effect on the child's development of trust or self-esteem (Tseng et. al., 1977). Children need to experience total acceptance during the formative years. Kelly (1963) summarizes this importance:

A child attempts to establish himself in relation to his parents. He winds up using the very same dimensional system his parents use. ( $p .177)$

Children meet the expectations of significant others through the internalization of the values, feelings and patterns present within the family system (Elkin, 1960). The child tends to feel that there is a right way to behave and think. The ability to identify with others is extremely important in the child's development of a positive selfconcept. If children develop negative self-concepts, it could influence their unconscious development of protective constructs, which could deter their ability to experience new things (U.S. Commission, 1975). The internal and social 
process of primary soclalization for chlldren presents an absolute truth of which an objective reality, parents or soclety has possession. Chlldren are not generally given the opportunity to discuss the reality they are taught. When asking questions, chlldren tend to get one answer which reinforces a dualistic perspective and ethnocentric attitudes. Hoopes (1981) refers to this as the "basic human survival response".

If parents of intercultural marriage are not aware of their own cultural differences, or have not discussed how these differences might influence their children, the effects could be detrimental (Bossard and Boll, 1957). Children are forced into situations where they must learn two sets of cultural roles, and/or two languages. How the parents handle the first six years of the child's upbringing is of the utmost importance in the child's process of establishing an identity (Christian, 1985). An example of this is the study by Bossard and Boll (1957) which showed that the majority of children did not stick with one decision regarding religion. A pattern of continual switching from one religion to the other, and in the end not practicing any specific religion at all was established. The offspring were unable to positively adapt to either religious perspective.

It has frequently been suggested that children of intercultural marriage are likely to develop psychological problems (Bossard et. al., 1957; Gordon, 1964; and 
Henriques, 1974). A study posed by Johnson and Nagoshi (1986) suggests:

... problems of cultural identification, of conflicting demands within the family, and of being "marginal" in both cultures are still said to exist for offspring of mixed marriages ... other negative influences ... such as personality problems of parents and increased marital conflict in mixed marriage, would also still be theoretically present. (p. 280)

Bossard et. al. (1957) indicate that raising children is the way humans preserve the identity of the society. Children raised in environments involving exposure to two different languages and cultures can experience personality problems. This is true specifically if the parents are unaware of their cultural differences, or have not agreed on how to raise the children. The parents may pull the child back and forth between them, continuously arguing over which value is valid, and why. Ambivalence and disagreement can create psychological problems such as marginality. Park (1928) describes the "marginal man" as:

... a man living and sharing intimately in the cultural life and traditions of two distinct peoples.... He was a man on the margin of two cultures and two societies which never completely interpenetrated and fused (p. 892).

Although Park's focus was on interracial mixtures, stonequist (1935) expanded, through continued research, on this concept. He deals with marginality as a function of social conditions, where conflict occurs between two 
different cultural systems. Stonequist (1935) offers a detailed definition:

... a process of abstraction, a core of psychological traltes which are the inner correlates of the dual pattern of social conflict and identification. (p. 10)

Harper (1986) also mentions stonequist's concept of marginality:

According to stonequist, the essence of the marginal situation is one of partial

assimilation and psychological identification with a dominant racial or cultural group without full acceptance from that group. Thus, these individuals find themselves on the margin of each society, partly in and partly out. (p. 34)

stonequist (1935) suggests a life-cycle process which involves crisis and adjustment. Lum (1982) defines a marginal person as "... one whose actions do not reflect well any culture" (p. 385). According to shibutani (1961), marginal people can experience doubts about personal worth, loneliness, constant fear of rejection, and painful selfconsciousness, which can lead to the development of personality disorders. Feelings of detachment from both cultures is also considered a common phenomena (stonequist, 1935). Children can experience soclety's negative response towards the intercultural marriage of their parents, either due to conflict this causes in the marriage, or problems of social adjustment among their peers. Couples who experience feelings of ambivalence, disagreement and social marginality can unknowingly transmit these feelings to their children through the socialization process (Yogev, Jamshy, and Hara, 
1983). Stonequist states that a child in this situation can experience continual questioning of social status. Her attention could be focused excessively on herself, leading to an increased self-consciousness as suggested by shibutani (1961).

\section{ADVANTAGEOUS IMPLICATIONS OF BICULTURALISM}

There are also positive aspects related to marginality discussed in the literature. Lum (1982) suggests that feelings of detachment enhance the ability to perceive new and different viewpoints, developing a more broadminded view. Ikeda (1985) supports Lum through the view that marginality gives a basis for the development of greater sensitivity. Lum finds this sensitivity prevalent in bicultural individuals.

After discussing the problems children of intercultural marriage may encounter, Ho (1984) continues with a discussion of the possible advantages. He suggests that children of intermarriage may have a greater awareness, recognition and acceptance of cultural difference. According to Ho, offspring ralsed in an environment involving exposure to two different ethnic and cultural groups, have the opportunity to learn and develop more perspectives. A child raised in a bicultural environment is exposed to different values, perspectives and linguistic expressions which form a psychic grid different than that of a child raised in a monocultural environment (Bruteau, 
1979). Intercultural offspring may have an increased sensitivity and acceptance of new ideas and behaviors. Lambert (1967) argues that:

Bilinguals, especially those with bicultural experiences enjoy certain fundamental advantages ... the child brought up bilingually and biculturally ... may well start life with an enormous advantage of having a more open, receptive mind about himself and other people. That is, he is likely to become especially sensitive to and leery of ethnocentrism. (p. 106)

Werner (1979) reinforces Lambert's argument. He feels that bilingualism and biculturalism enable children to recognize and develop a deeper understanding of how any given concept can be represented or associated with two different worlds, each representing an equaliy valid way. As sigel (1977) states: "The transmission of knowledge from one generation to another is one means of sustaining culture" (p. 4). Language is one of the avenues through which this knowledge is transmitted. The child learns to organize experience and cope with the world through language.

According to whorf (1956), language is reflective of reality. He identifies the linguistic system as both the reproducer and shaper of subjective reality. Once specific categories are set and expressed as a specific verbal or symbol of language, it is legitimate and becomes part of the collective stock of knowledge through reification (Berger and Luckmann, 1967). The more reified the concept, the more ethnocentricity possible. Access to two linguistic systems offers a wider set of boundaries. Focusing on the 
can serve to broaden a child's categories. A bllingual child experiences differences in language, which seem to enable the child to have different perceptions. Sigel (1977) suggests that children who learn two languages during primary soclalization also learn different patterns of relating to the world:

Perception, memory, and thinking all develop as part of the general socialization of a child and are inseparably bound up with ... communication and social relations .... (pp. 27-28)

socialization involving immersion in two cultural environments has been stated to have an impact on the children of Intercultural marriage (Harper, 1986). Tseng et. al. (1977) suggest that an awareness and understanding of differences which exist in an intercultural marriage can help people anticlpate, and possibly deal more effectively with problems encountered. They go on to present flve patterns of adjustment which occur in intercultural marriage, four of which require verbal communication between those involved. According to Tseng et. al., the role of communication is fundamental. Rohrlich (1988) supports this view, emphasizing that cultural awareness and communication about differences must be present in order to achieve greater intercultural sensitivity.

Following is a list of 22 themes discussed in this chapter. These themes were sallent in the preliminary thematic analysis of the literature and are broken down into advantageous and problematic implications of biculturalism. 
Advantageous Implications: Non-judgemental; more and broader perspectives; sensitivity and awareness of ethnocentrism; international awareness; greater awareness, recognition and acceptance of cultural difference; more open and receptive about self and others; greater sensitivity and acceptance of new ideas and behaviors; and bilingualism. (refer to Appendix A).

Problematic Implications: Culture conflict; partial assimilation of both cultures and marginality (as defined negatively in the literature); loneliness; identity confusion; detachment; indecisiveness; negative selfconcept; and increased self-consciousness and sensitivity. (refer to Appendix A). 
CHAPTER I I I

METHODS

\section{GENERAL METHODOLOGY}

This study will take an exploratory approach, utilizing a descriptive method of data collection, and a combination of Grounded Theory and ongoing Analysis as qualitative methods of data analysis. The purpose of this type of study is to develop new hypotheses, as well as generate information. According to Tucker, Weaver and Berryman-Fink, (1981):

... descriptive research involves the collection of information directly from individuals who possess the information ... The overall purpose of the descriptive method is to describe -- events, beliefs, attitudes, values... or behaviors. (pp. 89-90)

Data analysis is seen by Taylor and Bogdan as "... an ongoing process in qualitative research" (p. 128). This type of data analysis requires the researcher to simultaneously code and analyze the data. Through comparison of data, themes emerge, which the researcher first refines, and then explores further to determine the relationships existing among them.

There are three distinct phases in "Ongoing Analysis." In the "Discovery Phase", there are two tasks. The first is to identify emerging themes, and the second to develop 
concepts and propositions. The next step is to code and refine the data, and the final phase is to explore and understand the data within context.

Grounded Theory's strategy of theoretical sampling is also utilized in this study. As described by Taylor et. al. $(1984):$

In theoretical sampling the actual number of "cases" studied is relatively unimportant. What is important is the potential of each "case" to aid the researcher in developing theoretical insights into the area of social life being studied (p. 83 ).

According to Taylor et. al. (1984), Grounded Theory involves the generation and discovery of social theory and propositions from the data. "Researchers do not seek to prove their theories but merely to demonstrate plausible support for them" (Taylor et. al., p. 126).

The preceding methods are then used in five phases of research which involve the generation of themes, the development of research tools, and the analysis of results.

Phase one of the research involves the generation of themes from the literature through steps one and two of 'Ongoing Analysis' (refer to Appendix A). Based on the themes generated, the preliminary survey tool is developed in Phase Two utilizing the second type of data analysis (see Appendix B). The preliminary survey is developed to look for issues whlch arise concerning raising children in an environment with parents from two different cultures. In Phase Three, the researcher utilizes both research methods. First the researcher looks for new themes arlsing from the 
preliminary survey results; and second, selects themes from the literary review for follow-up in the interviews (refer to Appendix $C$ ). Phase Four involves the development of two interview schedules as data collection tools (see Appendices $E$ and $F)$. Due to the Iimited amount of literature and research avallable on families of intercultural marriage, and more speciflcally their levels of awareness and concern with issues of biculturalism discussed in the literature, an interview method of data collection is appropriate. Taylor and Bogdan (1984) also suggests that interviews are advantageous when there is a need for more complete and detalled answers. The qualitative method of data collection allows flexibility and spontaneity, providing more comprehensive observations (Dooley, 1984). According to Dooley, the comparison and contrast of different interviews enables the researcher to obtain a clearer understanding of the phenomena.

And finally, the information generated in the interviews is analyzed to generate additional new themes, and to provide empirical support for theories discussed in the literature. This final phase utilizes four categories of analysis described in the section on Data Analysis Procedures.

\section{SUBJECT SELECTION AND POPULATION}

The primary population of interest for this study are parents who are partners of intercultural marriage. Each 
couple consisted of one U.S., and one non U.S., partner. The non-U.S. spouse's first language was other than American English, and was born and spent the formative years of their lives outside American culture.

The second group of interest are children of couples who fit the above criteria. Taft (1981) refers to this population as Primary Familiogenic Multiculturals, children who experience simultaneous primary socialization in more than one culture due to one parent in the home coming from a cultural background different than that of the dominant society.

To obtain participants for this study, the techniques known as "snowballing" was utilized. According to Taylor et al (1984), this basic approach is one of the most feasible when working in private settings. A brief definition clarifles the "snowballing" technique: "... start with a small number of people, win their trust, and ask them to introduce you to others" (Taylor and Bogdan, 1984, p. 24).

This interviewer began with personal contacts. I was acquainted with four of the couples prior to beginning the study, the other six were introduced to me by friends and through other contacts. Prospective participants were contacted by the researcher, informed of the purpose of the study, and asked if they were interested in participating. subfects were then screened and chosen based on the selection criteria outlined below. 
Eighteen couples were screened according to the following criteria: country of birth, first language, country of residence during the formative years, and one or more children. Ten couples qualified based on the selection criteria. Selection criteria were also used to screen the second population of interest. Children were screened according to age and exposure to the first type of Primary Familiogenic Multiculturalism. Children between the ages of 13 - 19 were interviewed. This age group falls within the adolescent stage of developmental theories discussed by Kant (1985). During this stage children become more certain about sex roles, self, and values. Of the ten children initially screened, eight met the criteria.

Eight of the couples were composed of U.S. females and non-U.S. males, and the remaining two of U.S. males and nonU.S. females. All couples had been married at least three years and had at least one child. Only three of the twenty spouses interviewed had never visited their spouse's country of origin. The amount of time spent in the U.S. by the nonU.S. partner varied from six to forty years. One couple, consisting of a U.S. female and a non-U.S. male, withdrew from the study prior to the interview portion.

All children interviewed were either high school or college students. All had other siblings. Two of the eight interviewed had not visited the non-U.S. parent's country of origin, and only two were able to carry on a conversation in 
both parents' languages. One of the eight children withdrew from the study prior to the interview.

Based on the anonymity assured my subjects, they will be referred to by gender, as elther an American or NonAmerican, and by an assigned number. For example, individuals in the first couple will be referred to as NonAmerican Male or $\mathrm{N}$-AMl, and his American spouse as AFl. In the case of the couples they will also be referred to as Dyad 1 or D1. The second group of subjects will be referred to in a similar manner. For example, Yugoslavian-American male as $Y$-AM. See Appendices $G$ and $H$ for basic information regarding the subjects. Number of years married, sex, ethnicity, number of children, and number of years spent in the primary culture are factors included in Appendix G, and Appendix $\mathrm{H}$ lists parental ethnicity, age, gender, and time spent in each parents' country.

\section{THE INTERVIEW PROCEDURE}

This researcher conducted all aspects of this study. subjects were selected based on criteria outlined in the section on 'subject selection and Population'. Once screened, the families were sent a packet containing a cover letter, informed consent forms, and the preliminary survey. The preliminary surveys were administered to the adult population as general questionnaires.

The preliminary survey (see Appendix B) was developed to select themes for follow-up in the in-depth interviews, 
as well as to generate more themes to be considered and discussed in follow-up interviews. According to Tucker et. al. (1981), a survey is appropriate when information needs to be gathered directly from respondents who possess the information. Based on the paucity of literature and documented empirical information regarding subjects' experiences in intercultural families, this study required further information regarding the personal experiences, attitudes and behaviors of its' participants before administering an in-depth interview.

The preliminary survey used five closed and two openended questions which allowed for in-depth answers. The open-ended questions generated both information regarding the respondent's orientations towards the topic, as well as the aspects of biculturalism with which they are familiar. The questions also probed for subjective reports regarding communicative behaviors in relation to the study. This survey enabled the researcher to generate a focused interview schedule which was used in intensive in-depth interviews following the preliminary surveys. Families were Interviewed after all surveys and consent forms were returned.

The Interview schedules of questions were developed by the author based on the selection of themes which emerged from a qualitative thematic analysis of the literature and preliminary surveys. (see Appendices $E$ and $F$ for Interview Schedules) This researcher conducted all interviews, 
following an open-ended Interview schedule designed to explore the participant's subjective experience and awareness of the issues of biculturalism discussed in the literature, and their communicative behaviors in relation to the topic. Both Interview schedules contain a variety of open-ended questions which encouraged interviewees to share detailed information concerning their experiences as a member of a family of intercultural marriage. Interview Schedule I also includes five closed-ended questions asking for the couples verbal response on a Likert Type scale.

Each interview began with questions $1-7$. For the first population of interest, questions beginning in section I, and follow-up questions, are sequenced according to responses given by each of the interviewees to the preliminary surveys. For instance, if a couple marked that they discuss differences in their cultural backgrounds on the preliminary surveys, the interviewer would begin by asking question 8: "What are some examples of the differences you discuss with each other as they might affect your children?" Whereas, if couples reported never discussing differences, the interviewer would proceed with question 18 in Part II. "If you feel that no cultural difference exists, is it because you have already discussed or solved any issues that may have arisen?"

All questions on the second interview schedule were asked in sequence beginning with the first question and ending with a general open-ended question allowing 
participants to add any additional information regarding their experiences.

Couples were interviewed as a couple, and children were interviewed with participating siblings. The influence of reports will be considered in the data analysis in the Results and Discussion section.

Interviews ran an average of one to one and one half hours for the parents, and forty-five minutes to one hour for the children. The interviews took place in the subjects' homes or in a quiet setting which allowed for maximum interaction between the researcher and interviewees.

\section{THE INTERVIEW SCHEDULES}

The questions on both Interview schedules were designed to explore the respondents' awareness and concern with the attitudinal and behavioral characteristics attributed to children of intercultural marriage.

The conclusion reached in the summary of the literature review stated that both awareness and famillarity with the differences in each other's backgrounds, including expectations and perspectives, is desireable in an intercultural marriage. The absence of awareness and Eamiliarity with difference can lead to communication difficulties, both between the parents and among all family members. Questions 1 - 4 began the interview by asking about differences which are more commonly discussed and seen 
as less threatening as noted by Bennett (1986) and Barna (1988) in Chapter II.

1. Do you have any knowledge of the language of your spouse's country?

2. What contact have you had with people from your spouse's country?

3. How familiar are you with the social norms of your spouse's country?

4. Do you practice any of these norms, holidays, or customs in your household? Which ones?

The next three questions ask for the interviewees' own interpretations of biculturalism.

5. Do you consider yourselves bicultural?

6. Do you consider your children bicultural?

7. How would you define biculturalism?

As we found in chapter $I$, there exists great diversity in the literature regarding the concept of biculturalism. As we are looking at these families' awareness of the issues of biculturalism discussed in the literature, it is also of Interest to explore the subjects' understanding of the term "biculturalism". The responses to these questions will be compared with the literature, looking for a consistency of interviewees' perceptions with the literature review.

The aim of questions in the second section of Interview schedule $I$ is to elicit responses from the interviewees concerning the relevant issues of raising a child in such an environment. 
8. What are some examples of the differences you discuss with each other as they might affect your children?

9. What difference in your cultural backgrounds have led to conflict regarding raising your children? 10. If you solved these issues before you had children once you put your ideas regarding how to raise them into practice, did you find that you still had to deal with the same issues again?

These three questions build on the introduction through further follow-up and exploration of value differences experienced by each couple which are potentially more threatening.

Questions 11 - 21 (refer to Appendix E) are designed based on the salient concepts and themes discussed in the literature. These purposive questions seek to explore, first, the differences which the subjects experience; second, how these differences effect communication in the family; and third, how this could effect the children either positively or negatively (Bodger, 1984).

Questions in Part $A$ and $B$ of section II stem from responses to the preliminary surveys. This section was developed to elicit further information and as a follow-up on information generated during the preliminary surveys. Also included are generalized questions which provide cross checks for consistency of information reported by interviewees (Harper, 1986). 
Questions $11-17$ (refer to Appendix E) are created to ask specifically about the advantageous and problematic implications of biculturalism. The aim of these questions is to explore awareness and communicative behaviors couples report in relation to themes resulting from the previous analyses. (refer to Appendix C)

Part $B$ of section I I explores reports generated in the preliminary surveys that cultural differences are elther not experienced, or found insignificant by interviewees. Interview questions began by looking at differences in values and awareness of issues, and ended with questions pertaining to communicative behaviors. According to ErzenToyoshima (1986), people tend to be less aware and able to discuss their communicative styles and behaviors than differences in values. Therefore, section III was optimally placed towards the end of the interview, building on earlier discussion.

Questions 21 - 27 (see Appendix E) of the parents interview schedule corresponds with questions $17-20$ (see Appendix $F$ ) on the children's interview schedule. These questions were designed to pursue the second research question, focusing on the communicative behaviors of family members which is stated in the literature as fundamental to the achievement of intercultural sensitivity (Tseng et. al., 1977 and Rohrlich, 1988). Whereas the preliminary surveys asked couples to rate the occurrence of communication with regards to differences, questions $21-27$ on the parent's 
interview schedule utilize responses to the preliminary surveys, in an attempt to document communicative behaviors reported, and explore issues identified as important, looking for consistency with the research. Responses to section III are analyzed to see if there is congruency with the communicative behaviors discussed by Tseng et. al. (1977) and Rohrlich (1988) in Chapter II.

The children's interview schedule of questions was developed based on the themes generated in the literature and preliminary surveys (refer to Appendix $F$ ). The purpose of Intensive interviews with the second population of Interest is to provide empirical verification for issues discussed as signiflcant in the literature, and to look for consistency between subjective reports of significant issues and communicative behaviors by parents and the children.

Questions $1-3$ on the second interview schedule focus on experience with different aspects of both parents' cultures. The literature repeatedly discusses bilingualism as an advantage which further enables a child to experience the world in different ways (Lambert, 1967; Werner, 1979; and sigel, 1977). Whether children in this study speak both languages, and experience this as an advantage is also of interest.

Section II explores the children's experience of subjective reports of the inherent issues of biculturalism found in the primary analysis of the literature review and the preliminary surveys. In chapter I, we found that there 
is a paucity of information regarding the experience of children of intercultural marriages. How these children respond to and experience a bicultural upbringing; whether they experience the advantages of biculturalism; or whether they are aware of these issues has not been documented (Johnson and Nagoshi, 1986; and Rohrlich, 1988).

The third section of the children's interview schedule, as discussed earlier, deals with communicative behaviors of the family as reported by the children. Responses to the third section provide further information allowing an analysis focusing on the consistency of reports of awareness and communication made by the parents and by the children.

Question 29 on Interview schedule I and 21 on Interview schedule II ended the interview with a general open-ended question encouraging the participants to add any additional comment regarding their experience as a member of a family of intercultural marriage.

\section{DATA ANALYSIS PROCEDURES}

This study explores the interviewees' perceptions of their own experience and communicative behaviors as a member of a family of intercultural marriage. The study is concerned with the reported subjective experience of the interviewees. The results of this study are analyzed to see if responses to the research questions validate the significance of issues discussed as relevant in the 
literature and if they support new themes emerging from the preliminary survey.

Themes emerging from the analysis of the data are discussed in terms of advantageous and problematic implications of biculturalism following the pattern established in the literature review.

Themes emerging from the different phases of this study are reported and discussed in terms of four categories of analysis. The purpose of these categories is to allow the researcher to present new themes emerging from the data, and provide empirical support for themes discussed in the literature. These categorles are presented in the discussion sections of Chapter IV.

Category I refers to themes which arose in the literature review, but were not mentioned in the preliminary surveys; Category I I includes themes prevalent in both the literature review and the thematic analysis of the preliminary surveys; Category II refers to new themes generated in the analysis of the preliminary surveys, but not reflected in the Iiterary review; and Category IV reflects new themes generated in the follow-up interviews. 
CHAPTER IV

\section{RESULTS AND DISCUSSION}

The purpose of this study was to discover whether families of intercultural marriage are aware of the implications of biculturalism identified in the literature.

The following chapter includes reporting of results found through the data analysis procedures described in Chapter III, and discussion of the congruence between themes generated in the three stages of data analysis: analysis of the literary review, preliminary surveys and the follow-up interviews. Themes emerging from the interviewees are reported in terms of the four analytical categories, broken down into advantageous and problematic implications as discussed in the last chapter. The major salient themes found are discussed in depth with quotations from preliminary surveys and interview data used as illustrations in support of these results.

The first phase of ongoing Analysis is known as the Discovery Phase. This phase involves examining the data, noting themes and patterns which emerge, and developing concepts or theoretical propositions. The primary analysis of the literature revealed twenty-two salient themes which were separated by the researcher in terms of the 
advantageous and problematic implications reported in Chapter II.

\section{PRELIMINARY SURVEY RESULTS}

Results from the preliminary surveys revealed that eight of the ten couples reported discussing differences with each other, or with their children, once a month or less. On a Likert Type scale of 1 (not at all important), to 5 (very important), $90 \%$ revealed that they felt differences in their cultural backgrounds were of little significance in the process of childrearing, averaging an overall mean of 2.0 .

Upon breakdown of couples based on their childrens' ages, the researcher found that $100 \%$ of couples with children under the age of 13 reported that communication between the spouses about cultural differences occurred once a month or less. All of the couples reported having never discussed cultural differences with their children. The negative aspects of biculturalism were discussed by $25 \%$ with their spouse, and $50 \%$ reported having discussed positive aspects of biculturalism with their spoues. An average score of 1.5 reflected the importance assigned to cultural differences in the process of childrearing.

An increase in importance of communication was noted in the responses of couples with children age 13 and older. Approximately $83 \%$ reported having discussed cultural differences with each other or with their children. Eighty- 
three percent also reported having discussed positive aspects of biculturalism with each other from seldom, to as often as once a week. Whereas $75 \%$ of couples with children under 13 years of age had never discussed negative aspects of biculturalism with their spouse, this figure decreased significantly to $33 \%$ for couples with children 13 years of age and older. The average mean score of importance of cultural differences in the process of childrearing by couples was $2.5,1.0$ higher than that of the first group. Included below is a table charting the mean on the five point Likert Type scale used.

TABLE I

OVERALL RESPONSE MEANS

OF THE PRELIMINARY SURVEY

\begin{tabular}{lccc}
\hline & Mean & $\begin{array}{c}\text { Couples with Children } \\
\text { Under } 13 \text { Years }\end{array}$ & $\begin{array}{c}\text { Couples with Children } \\
13 \text { Years And older }\end{array}$ \\
Question: & 2.15 & 2.0 & 2.3 \\
1. & 1.8 & 1.0 & 2.7 \\
2. & 2.0 & 1.5 & 2.5 \\
3. & 1.9 & 1.25 & 2.3 \\
4. & 2.4 & 1.75 & 2.8 \\
\hline
\end{tabular}

$\mathrm{n}=10$ couples

Variances range from a .3 increase when discussing differences with spouses, to a 1.7 increase in communication about cultural differences with children age 13 and older. These tabulations show that there was an increase in communication about differences and issues of biculturalism within families of intercultural marriage whose children were 13 years of age and older. 
Two open-ended questions (refer to Appendix B)

generated new information which was then analyzed for validation of themes found in the literature review, and for new themes emergent in the data.

The thematic analysis of the preliminary survey yielded 11 salient themes (refer to Appendix $C$ ). Six of the themes which emerged directly from information shared by the informants corresponded with themes found in the literature review, and are significant according to the earlier analysis of the literature. These six themes are discussed as Category II, issues found prevalent in both the literature and preliminary surveys, in the following discussion section.

Two problematic issues of biculturalism discussed in the preliminary analysis of the literature were reported as negative aspects discussed between spouses. Twenty percent said that their children's inability to truly understand the non U.S. culture was indeed problematic. The second issue mentioned was that of identity confusion. Four advantageous issues were also mentioned in response to the preliminary surveys. Parents felt that their children had learned to tolerate prejudice through personal experiences. A further $20 \%$ also reported their children benefited from greater international awareness. A positive aspect of raising children in a family of intercultural marriage was stated as broadened horizons and perspectives by $30 \%$ of the couples, referencing the second issue 1 isted in the 
preliminary analysis of the literature. Couples also mentioned bilingualism as an advantage, although only $10 \%$ of the above $30 \%$ cited have raised their children in a bilingual setting. Lastly, $40 \%$ of the ten couples reported greater awareness of different cultures and customs as an asset for their children.

The remaining five themes emerged from patterns of two or more consistent reports by informants. Four new themes arose under advantageous issues. Exposure to a variety of foods was repeatedly mentioned by $40 \%$ as a positive aspect of raising children in such an environment. Four couples listed a positive aspect as the interest in and more opportunities for travel abroad their children have due to extended family living abroad. And finally, two couples stated that a definite advantage was that the children learned to question home cultural values.

The fifth theme emerged under negative aspects of raising children in an environment with parents from two different cultures. Four couples mentioned communication problems children experience due to their not being bilingual in both parents' native languages. According to these couples, the child unable to express himself in both languages encountered communication problems such as misunderstanding of words and idioms. The inability to communicate with extended family members, such as grandparents, is seen as a definite disadvantage. 
The five new themes generated in the preliminary survey provided follow-up issues for the interview schedules and were then incorporated into the final list of themes found in Appendix $D$.

\section{PRELIMINARY SURVEY DISCUSSION}

\section{Overview}

In terms of the second research question, overall results of the preliminary surveys showed that cultural differences, as well as issues of biculturalism, are seldom discussed among families of intercultural marriage.

Results also indicated that positive aspects of raising children in an environment with parents from two different cultures appear to be discussed between parents more often than negative aspects. Furthermore, cultural differences were deemed as relatively unimportant in the childrearing process, a finding which conflicts with the literature. Explanations of this may be that couples tend to assume and focus on similarities rather than differences, or that they experience a confusion between cultural versus personal differences. This can be seen in the following quote:

None to do with cultural differences. we had differences, but more of personality than cultural. (D6)

Upon breakdown, however, the results revealed that parents with children 13 years of age and older considered cultural differences more important than those couples with younger children. Perhaps the parents awareness of these 
differences increases due to increased conflict within the family as children experience adolescence. In adolescence children focus on developing a self identity separate from their parents. They become more concerned with who they are and why. As parents try to answer questions and assist their childrens development during these years, differences in values could arise. During these stages, cultural difference would become a more evident and important issue to the parents. Results also revealed that as the children grow older, parents are more likely to discuss cultural difference with them. Assuming these results are related, an increase in communication among family members would be ideal according to the earlier discussion of Erikson's views on good adjustment in adulthood.

\section{Categories}

Eleven themes surfaced among responses to the openended questions in the preliminary surveys. Five new themes which were not discussed in the literature are incorporated in category III. The other six themes represented category II, themes found prevalent in both the literature review and the analysis of the preliminary surveys. Salient themes in Category II were labeled in accordance with themes established in the preliminary thematic analysis of the literature. of the themes listed in the preliminary thematic analysis of the literature, $37.5 \%$ (see Appendix A) were mentioned in the preliminary surveys. Category I is represented by ten themes which were found in the review of 
the literature, but not supported in the preliminary surveys (refer to Appendix $D$ ). These themes were not intentionally followed up in the interviews.

According to the second and third categories of analysis, the following themes were salient in the preliminary surveys:

Category II: Advantageous Implications - Nonjudgementality; more and broader perspectives; international awareness; bilingualism; and a greater awareness, recognition and acceptance of cultural difference. Problematic Implications - Identity Confusion. It appears that these six themes found in the literature review are supported and will be looked for in the follow-up interviews.

Category III: Advantageous Implications - Exposure to a variety of foods; the opportunity and increased interest in travel abroad; and learning to question home cultural values. Problematic Implications - Monolingualism; and the inability to truly understand the "foreign culture."

Category III refers to new themes that emerged from the preliminary surveys but were not reflected in the literature review. This category generated five new themes. 


\section{PARENTS ' INTERVIEW RESULTS}

Results from Section I of the Parents' Interview schedule follow. Only four of the nine couples interviewed reported frequent contact with people from the non-U.S. spouse's home culture, including family and friends. Three reported having no contact at all, and the remaining two, very little.

The non-U.S. spouses have resided in the U.S. for a total of six to forty years, whereas the longest period spent in the partner's culture by a U.S. spouse was two years. Six having spent a total of one to eight weeks in their spouse's country of origin, and two reporting no experience in the other culture.

All non-U.S. partners reported fluency in American English. However, only four U.S. spouses reported fluency in their spouse's first language. Two partners had very limited knowledge consisting of a few words or phrases, and the remaining three reported no knowledge of their spouse's first language.

The final questions discussed in section I looked at familiarity with and practice of holidays, customs and norms within the household. Of the U.S. spouses interviewed, $77 \%$ reported familiarity with the major holidays of their nonU.S. spouse's culture; 668 discussed specific customs they are aware of, and $55 \%$ were able to pinpoint norms of the non-U.S. culture with which they are familiar. Of the nonU.S. spouses who claimed familiarity with American holidays, 
customs and norms, $100 \%$ were due to the extended period of time they have resided in the U.S.. Although a high percentage claimed familiarity with these differences, only $44 \%$ reported practicing a mixture of both spouse's holidays, customs and norms within their households.

According to the remaining $55 \%$ of the couples, practice of American holidays and customs predominates, although $22 \%$ reported practicing customs and norms when in the company of others from the spouse's culture, either in the home or when traveling abroad.

of the aforementioned $44 \%$ who reported a strong mixture of both cultures, $75 \%$ appear to share one factor in common. These families report frequent exposure to family and friends of the non U.S. spouse. Furthermore, $50 \%$ represents couples who are fluent in the native language of the non U.S. spouse, with another $25 \%$ reporting fluency of understanding, but a lower speaking ability. other factors considered which did not show further correlations were age of the children, time spent in spouse's culture, and the number of years married.

The last three questions in section I directly explore the interviewees understanding and experience of biculturalism. When asked to define biculturalism, a typical response was: "... the ability to communicate and be a part of two different cultures" (N-AM7). other variations included responses such as: "Feel comfortable Iiving in either culture" (N-AF8); "Not to feel completely 
at odds" (AF9). And finally, two couples discussed the ability to be accepted by others in the culture as necessary: "Be able to pass for a native; move in any circle" (N-AM9); "Having an understanding of and being able to act correctly if one chooses in both cultures. Needs to be objectively accepted by others in the culture" $(\mathrm{N}-\mathrm{AM} 3)$. These two expressions are consistent with Ikeda, who describes a bicultural person as being able to behave appropriately in each culture.

Exposure and contact with both cultures was stated as necessaryby 33\%, as well as daily use of customs, norms and cultural roles. Furthermore, $77 \%$ mentioned language as a required element in biculturalism. Although only $11 \%$ reports having raised their children bilingually, $44 \%$ stated that they consider their chlldren to be bicultural. When asked whether they consider themselves to be bicultural, $66 \%$ of the U.S. spouses replied no, and $77 \%$ of the non U.S. spouses replied yes.

section I of Interview schedule I was aimed at exploring Interviewee's experiences concerning raising children in an intercultural marriage. Questions 8 through 10 further pursued responses to the preliminary surveys, looking specifically at cultural differences experienced, and discussed between the spouses. Of the $44 \%$ who stated that there were no specific cultural differences, $50 \%$ reported confusion between personal versus cultural differences. 
... none to do with cultural difference. We had differences, but more of personality ... we tried to focus on similarities rather than differences. (AF6)

This finding supports the discussion of results in the previous section. The remaining $55 \%$ reported a variety of cultural differences. Differences in family structure and the value placed on family as an issue which had arisen was discussed by $33 \%$. The entire $33 \%$ were made up of families with children under 13 years of age. Response patterns are exemplified by the following statements: "Difference in family structure - the roles of family members" (N-AM3); "Family. How much do you include the child.... My family will spend more, will allow the child to do more and be a part of the family" (AF9); "Children need to learn both structures. For example, respect for the elderly, kissing older relatives hands" (AM1). The push of society along with differences in educational systems, or how education is viewed was mentioned by 22\%. And finally, $44 \%$ discussed roles of the children, typical responses resembled: "Differences in expectations of how to raise the children" (D7).

Questions 9 and 10 elicited individualized responses which were not of significance. The questions were either not applicable to the interview, or couples did not respond to the questions.

The next question focused on aspects of biculturalism generated in the preliminary surveys. Twenty-two percent indicated that they were aware of the positive aspects prior 
to having children. These aspects included bilingualism, biculturalism, awareness and understanding of different cultures, broadened horizons, and the increased opportunity for travel. Of the $22 \%, 50 \%$ reported discussing the issues with their spouse. The remaining $50 \%$ had not discussed these aspects: "Because they are so obvious and selfevident" (N-AM4).

Seventy-seven percent indicated they became aware of positive and negative aspects through experience. Following are examples of these indications: "We encounter differences through trial and error" (N-AM1); "Through experience, then we discuss it with each other as they come up" (N-AM 3 ); "Raising children forced us to discuss these issues during the later years ... we discussed issues and then made the best decisions possible" (D7). As indicated in the above responses, $55 \%$ reported discussing issues at the time experienced. The remaining $22 \%$ thought about and discussed it as a result of the preliminary survey questionnaire.

Those listing negative aspects of raising children in an intercultural marriage responded with examples of how they attempted to overcome the negative aspects listed in their questionnaires. Examples included exposure to family and or friends of the non U.S. culture, familiarity with some of both languages, and communication between the spouses. Of the couples who listed positive aspects of raising children in an environment with parents from two 
different cultures, $100 \%$ indicated methods through which they had attempted to ensure their children would benefit from these positive aspects. A mixture of role-modeling, association, and then discussion with children was used by 33\%. Having the children learn a second language was mentioned by 33\%. Communication with their children about differences was felt an important part of the process by 50\%. Furthermore, $83 \%$ suggested that exposure to different cultures ensured that their children would benefit from the positive aspects previously listed. The following responses were given regarding this advantage:

Travel and exposure to different cultures different foods ... once you are exposed to something different, your taste buds are more attuned to trying different things. (N-AM6)

Exposure to differences. We point out the differences within one culture as well. (AM8)

I'm like a horse with those visors that just sees in one direction you know, and the child will have that while the child is growing up. The child will see mom, daddy and grandma and others as well.... (N-AM5)

In response to question 14, inguiring how communication or prior awareness about these aspects was advantageous for their children, $22 \%$ indicated that the more communication between parents of these issues, the better and easier it is for the children to understand.

The final three questions in part A focus on the childrens awareness of aspects of biculturalism. On a Likert Type scale, ranging from 1 (not at all aware), through 5 (very aware), parents indicated the awareness 
levels of thelr children regarding negative and positive implications. Responses yielded that parents considered their children to be more aware of positive than negative aspects, with a mean score of 4.7. Negative aspects mentioned revealed a mean score of 2.2 . Of the couples with children under 13 years of age, $50 \%$ did not respond to the question about negative aspects, whereas $100 \%$ of these couples did not respond to the question rating awareness of positive aspects. Couples with chlldren 13 years of age and older scored awareness by children of negative aspects at 3.0. However, children's awareness of positive aspects was considered to be much higher by these parents, yielding an mean score of 4.7 .

\section{TABLE I I}

PARENTS' PERCEPTIONS OF THE AWARENESS OF ISSUES OF BICULTURALISM BY THEIR CHILDREN

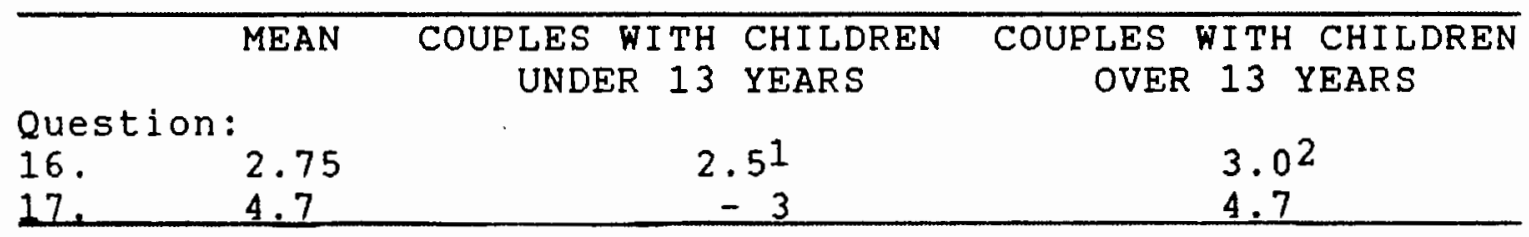

$\mathrm{n}=9$ couples $1_{n}=2$ couples $2_{n}=4$ couples

3 no responses

The final question in Part A explored the positive and negative aspects of being raised in an intercultural marriage which couples felt their children actually experience. Responses to this question yielded positive aspects experienced. Thirty-three percent of couples with 
children under 13 years of age failed to respond. An increased flexibility or ability to adapt was mentioned by 33\%. An awareness and understanding of different cultures, people, or differences in general was indicated by $44 \%$. Following are responses indicative of these results: "The child experiences different cultures ... exposes himself more to other cultures based on his primary experience" (NAM4); "... helps them develop an understanding of others' differences. This is fundamental to human understanding" (D7). And lastly, 44\% stated that exposure to a different language or bilingualism was a positive experienced by the children.

Section B further explores reports suggested in the preliminary surveys that cultural differences are either insignificant or not experienced. Question \#18 asked if the reason they felt no cultural differences existed was due to earlier discussion of the issues. This question yielded no responses.

When asked to rate the importance that the children are aware the parents are from different countries, a mean score of 4.3 evolved. Upon breakdown, parents with children 13 years of age and older assigned a higher score, yielding a mean of 5.0 in contrast to 3.6 assigned by parents with children under 13 years of age.

The next scale question asked for the parents to score the Importance of their children being aware of different cultures, customs and ways of life. An overall mean score 
of 4.75 was assigned. Once again, parents with children 13 years of age and older scored the level of importance higher than parents with younger children, yielding a 5.0 versus a 4.5 score. In exploring variances in responses, $75 \%$ of spouses with children under 13 scored each question separately, varying as much as 3 full points in their responses to this issue.

TABLE III

PARENTS' PERCEPTIONS OF THE IMPORTANCE OF THEIR CHILDREN'S AWARENESS OF DIFFERENCES

\begin{tabular}{|c|c|c|c|}
\hline MEAN & $\begin{array}{r}\text { COUPLES WITH } \\
\text { UNDER } 13\end{array}$ & $\begin{array}{l}\text { CHILDREN } \\
\text { YEARS }\end{array}$ & $\begin{array}{c}\text { COUPLES WITH CHILDREN } \\
\text { OVER } 13 \text { YEARS }\end{array}$ \\
\hline $\begin{array}{ll}\text { Question: } \\
20 . & 4.31 \\
21 . & 4.75 \\
\end{array}$ & & $\begin{array}{l}.6 \\
.5 \\
\end{array}$ & $\begin{array}{l}5.0^{2} \\
5.0 \\
\end{array}$ \\
\hline
\end{tabular}

$\mathrm{n}=9$ couples

$1_{n}=8$ couples

$2 \mathrm{n}=4$ couples

When asked why they had not experienced any significant differences, $33 \%$ cited flexibility and openness: prior exposure to different cultures; and $50 \%$ discussed the amount of time spent in the U.S. culture by the non-U.S. spouse as an important consideration. Other explanations included: age of the child; a focus on childrens ability to function in this society; extreme ethical differences not encountered; and the parents focusing on similarities rather than differences. Of the couples responding to this, $67 \%$ were parents of children under the age of 13 .

Section II of Interview schedule I explores communicative behaviors reported and issues identified as 
important by subjects. A final close-ended question asked the subjects to score the importance of their children being aware and able to discuss differences with others. The overall mean score at 4.6 , with couples of children above the age of 13 assigning a 5.0 (very important), and couples with younger children assigning a mean of 4.25 on the five point Likert Type scale.

TABLE IV

PARENTS' PERCEPTIONS OF THE IMPORTANCE OF DISCUSSION ABOU'T CULTURAL DIFFERENCE

\begin{tabular}{ccc}
\hline MEAN & COUPLES WITH CHILDREN & COUPLES WITH CHILDREN \\
& UNDER 13 YEARS & OVER 13 YEARS
\end{tabular}

Question:

22 . 4.6 4.25 5.01

$n=8$ couples
$1_{n}=4$ couples

The second half of this question explored their explanations for scoring. In exploring the remaining responses, $25 \%$ felt that awareness and the ability to discuss cultural differences enabled the children to express themselves more intelligently. Parents also felt the children learned to highly appreciate and respect differences. An increased curiosity or inquisitiveness on the part of the children, as well as a demonstrated openmindedness to other cultures was mentioned by $37 \%$. Half of the interviewees indicated that awareness and open discussion enabled the children to learn more about other cultures, and increased the children's understanding regarding why things are done differently in other cultures. 
Furthermore, $62 \%$ suggested that awareness and the ability to discuss differences encountered, made the children better communicators overall.

The following question explored the parents reasons for discussing or not discussing differences with their children. Three different advantages including an increased flexibility, learning about their heritage, and a deepened respect and appreciation of differences of others was yielded by $33 \%$. An awareness of different cultures, therefore offering more choices was cited by $50 \%$ as a reason for discussing differences with the children. Eighty-three percent stated that discussion gave the children an increased understanding of differences. However, discussion alone was not considered to be enough according to several subjects.

Discussion is important, but the children need to experience both cultures, then we can more easily discuss it. Communication is not enough ... it is hard to explain. (D2)

Discussion and exposure goes together. When you are exposed to different things you have to discuss it ... communication leads to appreciation and understanding.... I wouldn't think of reasons for not discussing it. (D6)

Question 24 yielded responses from $33 \%$ of the couples, all of whom have children 13 years of age and older. The entire $33 \%$ reported discussing differences in their childhoods or beliefs as relevant to the childrens' life experiences.

Two out of the nine couples responded to question 25 , asking for examples of differences discussed with their 
children. Those who responded referred back to question 8 , citing that all the differences they previously experienced and discussed with each other, had also been discussed with the children.

of the five couples responding to question $26,40 \%$ reported having discussed differences in educational systems and how success differs with their children. Forty percent revealed that they intended to discuss differences in cultures with their children, and $60 \%$ indicated discussing the advantages of bilingualism or learning a second language.

Questions 27 examined how interviewees with children under 13 years of age plan to discuss positive and negative issues as their children grow older. Discussion of different behaviors and differences in general was mentioned by 50\%. Curiosity by the child and exposure was reported by 100\% of the couples. Typical responses included: "When the child asks the questions" (AFI); "I think that more exposure to my country will spark question" (N-AM); "If they ask questions, then we'll discuss it more" (AM2); "Through experience ... and when she asks the questions" (AF9).

Four out of the nine couples responded when asked how their children became or will become aware of differences if it is not discussed. Of those who responded, $75 \%$ cited experience and exposure to the differences as a major contribution towards the child's awareness level. Other responses included reminding children that they could lose 
the advantages, such as language; role-modeling; and trying to establish different thinking patterns more on the positive.

The final question encouraged subjects to add any additional information they felt important regarding their experience in an intercultural marriage. This question was open-ended. All seven couples responding discussed advantageous or positive aspects for both themselves and their children. Typical responses included: "Our children are very different and respect each others' differences. This comes from exposure to cultural differences" (D7); "She'll be more sensitive" (N-AM5); "He is American, but at the same time he is very open and flexible" (N-AM4); "I'm much richer for it, and I think the kids are also" (AM8).

\section{PARENTS' INTERVIEW DISCUSSION}

\section{Overview}

In response to the first research question, $47 \%$ of the implications of biculturalism discussed in the literature were verified by couples of intercultural marriage. In general, the results of the follow-up interviews with nine couples tended to be consistent with results from the preliminary surveys, providing further support for theoretical propositions found in review of the literature.

Two of the nine couples reported an awareness of advantageous implications of biculturalism before having children, of which one couple indicated having discussed the 
issues. The remaining seven couples became aware through the experience of raising children in an intercultural marriage. Five couples reported actually discussing these issues with one another.

That $50 \%$ of the couples indicated they discussed advantageous aspects with their children is less supportive of the literature than was anticipated. However, $83 \%$ highly valued the use of "exposure" which is noted by Bennett (1986) as an important concept within his developmental model of intercultural sensitivity. Spouses also reported discussing problematic implications with one another, and not with their offspring, which implies that the children should demonstrate a higher awareness of advantageous versus problematic issues. This will be explored in the discussion section of the children's interviews in an attempt to answer the third and fourth research questions.

In general, the subjects' understanding of biculturalism tended to be consistent with the literature, although the researcher found one inconsistency among reports regarding the role of bilingualism in being bicultural. That $77 \%$ indicated bilingualism as a necessary element in biculturalism, and $44 \%$ of the above stated they consider their children to be bicultural, conflicts with reports that only $11 \%$ of those reflected in this percentage reported having raised their children bilingually. However, the interviews led the researcher to suppose that this inconsistency was due to a combination of responses 
regarding the "ideal" and the "real". In order to be a perfectly balanced bicultural, parents tended to feel bilingualism was necessary. According to the couples, however, the fact that their children are not bilingual, does not mean that they do not experience other aspects of biculturalism.

\section{Categories}

Following is a discussion of the themes selected for follow-up based on the results of the preliminary surveys. A 1 ist of these themes can be found under category II, themes found prevalent in both the literature review and preliminary surveys. Also included in Category II are two new themes generated in the interview phase.

Category II: Advantageous Implications - Nonjudgementality; broader and more perspectives; international awareness; bilingualism; greater awareness, recognition and acceptance of cultural differences; open and receptive about self and others; and a greater sensitivity and acceptance of new ideas and behaviors. Problematic Implications Identity confusion.

Although the issue of identity confusion was directly reported by only one of the ten couples, considering the generality of the question, and the significance of this issue in the literature, this theme was incorporated under Category II. There are several references to the issue of identity throughout chapter II. Kelly (1963), for one, states: "A child attempts to establish himself in relation 
to his parents" (p. 177). The child internalizes the values, feelings and patterns within the family systems. When these patterns, feelings or values are conflicting or differ in intensity, an unaware child can experience identity confusion.

The final five themes verified in the preliminary surveys consisted of advantageous implications of biculturalism. Reports of a learned tolerance to prejudice and difference are consistent with previous discussions by Harper (1986) and Lambert (1967) found in Chapter II. According to Lambert, these children experience the advantage of a more open and receptive mind. Children were also stated to have broadened horizons and perspectives by their parents, validating the second theme listed in the thematic analysis of the literature. Ho (1984) mentioned that children raised in such an environment have the opportunity to develop more perspectives which is supported further by Bruteau (1979). Ho's proposal that children raised in an environment with exposure to two different cultural groups develop a greater awareness, recognition and acceptance of cultural difference was also supported by reports in the preliminary surveys. Bilingualism was revealed as an advantage by a high percentage of the population, validating earlier findings by Harper (1986) and Werner (1979).

Two themes from the literature review which were not supported in the preliminary surveys were included in 
Category I d during the interview phase. Reports by couples of flexibility or an ability to adapt demonstrated by their children is supportive of two advantageous implications mentioned in the literature review and included in category I. The nature of this response is supportive of themes coded as "open and receptive about self and others"; as well as a "greater sensitivity and acceptance of new ideas and behaviors". Lambert, (1967), Bruteau (1979) and Harper (1986) discuss these implications as interrelated in the pattern of development experience by children raised in an intercultural marriage.

Category III: Advantageous Implications - Exposure to a variety of foods; increased opportunity and interest in travel abroad; and learning to question home cultural values. Problematic Implications - Monolingualism and the inability to truly understand the "foreign culture".

Category III consists of five new themes generated in the preliminary surveys, and further clarified in the interviews. Following is a discussion of these themes.

Monolingualism was discussed in terms of communication problems encountered. As mentioned earlier, couples reported that their children were unable to express themselves in both languages, which led to communication problems within the family. The child has learned one primary pattern of relating to the world, that of the primary culture. In this case, U.S. culture. The child could very well experience communication problems with the 
non-U.S. parent, similar to those experienced between the spouses of intercultural marriage. This could lead to further negative implications discussed in the literary review including alienation within the family, or even feelings that the U.S. parent is more understanding than the non-U.S. parent. Another factor which should be considered is the amount of time spent in the non-U.S. culture by the child(ren). The inability to speak the non-U.S. parent's native language, combined with inexperience, or very little experience in the culture could attribute towards a disinterest, as well as communication problems with people from the other culture.

Reports by couples that their children are unable to truly understand both parents' cultures can be seen as similar to the problem of partial assimilation of both cultures discussed by stonequist and noted in chapter II. According to stonequist (1935), individuals unable to fully assimilate or identify themselves with a dominant cultural group are not accepted by the group, creating a life-process of crisis and adjustment wherein the individual appears stranded on the margin or border of the culture. stonequist specifically focuses on those on the margins of two societies. However, his ideas are applicable to the situation of an intercultural marriage, where the child experiences dual patterns or systems within the family. The child unable to truly understand and identify with both parents' systems could very will experience such problems. 
The opportunity for, and increased interest in travel, as well as exposure to a variety of foods were also perceived as advantageous by subjects. These themes are included in Category III. An explanation of this may be that travel and exposure to other cultures is seen by many as an overall education which creates an opening of the mind through exposure to differences in living styles, foods, behaviors, and values. As noted earlier, exposure to difference can lead to a lessened ethnocentric stance of prejudicial attitudes, as well as increase one's willingness to place themselves in situations where their own values are threatened. This, in turn, may initiate questioning of ones' own values as "the best way", which is discussed by Bennett (1986) as an important aspect in one of the initial steps to overcoming an ethnocentric stance.

Category IV, new themes generated in the interviews, is not discussed in this section as there were no new themes generated which fit this category.

\section{CHILDREN'S INTERVIEN RESULTS}

Results yielded from section I of the children's Interview schedule indicated that their direct experience with the non-U.S. parent's culture was indeed limited. Of the seven children interviewed, one had spent two years in the non-U.S. culture; four had spent less than 12 weeks in their non-U.s. parent's homeland; and two reported no experience abroad. Furthermore, three of the seven revealed 
that they had no knowledge of the non-U.S. parent's primary language; three reported familiarity with a few words and phrases; and one reported total fluency or being bilingual. All interviewees had other siblings.

The first two questions in section II were open-ended, yielding several significant themes. When asked what things they liked about having parents from two different cultures, $43 \%$ of the children, in various configurations, mentioned each of the following topics: extended family abroad, which often enables travel; exposure and discussion of two different points of view or differences in general, lead to more thought; the ability to question and examine more closely; that having parents from different countries made them "unique"; and that it gave them more choice. Of the group, $29 \%$ also mentioned exposure to different foods, heritage and history, and the insight gained into existing differences.

Discussion of dislikes revealed that $29 \%$ felt displaced. Forty-three percent stated that the different cultures seemed to cancel each other out, or cause confusions. Following are responses indicating this confusion: "We do have elements from both cultures, but neither is very strong" (D-AF); "The two different points of view we get can be really confusing" (Y-AM); "It has produced a cancelling out of traditions rather than fusion" $(D-A M)$. 
one individualized response of significance stated that not being raised bilingually was a disadvantage. And finally, 57\% indicated that having parents from different cultures provided for conflict. Of the above $57 \%, 75 \%$ discussed conflict between the child and the non U.S. parent, the remaining $25 \%$ referred to conflict between the parents. Furthermore, 75 stated that the U.S. parent was more understanding.

seventy-one percent identified themselves as an American, the other $29 \%$ as a hybrid. Of the $71 \%$ who felt strongly American, $40 \%$ felt they had values and characteristics of the non-U.S. parent's culture; $40 \%$ mentioned a strong interest and tendency to identify with people, things or ideas from the non-U.S. culture; and $40 \%$ Indicated that although they feel 'American', they Identify and feel a sense of belonging with their non-U.s. family.

Forty-three percent consider themselves to be bicultural. When asked whether they consider their parents to be bicultural, $86 \%$ responded yes to the non-U.s. parent, and $29 \%$ considered their U.S. parents bicultural.

The next question required the subject to define biculturalism. Of the six children who responded, $67 \%$ described it as a knowledge of the two cultures involved, and the ability to function in both cultures. Language was also stated as a necessary element by $67 \%$.

Six children responded to question 11 asking for specific experiences when they noticed important differences 
between their parents. Of these six, 33\% mentioned role expectations as an important difference between their parents. Fifty percent indicated that important differences they observed involved how to raise the children, specifically what appropriate behaviors were, and how the parents dealt or communicated directly with the children. Following are responses reflecting feelings expressed:

"Fell, different ways they deal with us. She talks with us about feelings, he never does" (Y-AF); "They had different ideas in how to raise us ... this was obviously cultural" (H-AM).; "Dad gives us advice ... "do it this way", rather than listening to us.... I thought all parents were like this" $(Y-A M)$.

Question 12 generated many individualized statements regarding differences between the children and their Eriends. Of the five subjects who responded, $40 \%$ discussed differences in customs. Examples varied from the prom to daily household habits. Forty percent reported discussing these differences with their parents, and $60 \%$ with siblings.

The last four questions in section I were open-ended, exploring the children's subjective reports of important issues regarding having parents from different countries. six of the seven subjects responded. When asked the effect this had on them in general, seven significant themes arose. Three themes were discussed by $33 \%$ of those responding. The first, described a feeling of freedom -- not being tied to anything specific due to a lack of traditions. Secondly, 
subjects felt freer from ethnocentric and prejudicial

attitudes. And third, children revealed that they were more worldminded, or more aware of the world than other kids their age. A strong interest in other cultures was Indicated by 50\%. The $f$ ifth theme, being more open-minded and expanded, represented a further $50 \%$ of responses. In addition, $50 \%$ of the subjects felt they had developed an awareness of differences, as well as a deeper understanding of them. And finally, $83 \%$ stated that having parents from two different countries gave them the ability to look at things from different perspectives. Following are quotes expressing these opinions: "It's almost as if one surveys the options and can treat them equally, with equal fairness ... I don't feel like there's anything that's come before ... It's just starting here and now" (D-AM); "I can see different perspectives, different ways of living. If my dad was American, I wouldn't be aware" (Y-AF); "I'm more aware of the U.S. ... can take on different perspectives" (I-AF). In addition, subjects responded similarly when asked the most important things they had learned about other countries. Eighty-six percent stated differences in perceptions, behaviors, style of living or principles. Themes such as historical aspects; to be less ethnocentric; and a realization or consciousness of values was represented by 29\%. The last two questions in section I focused on the advantages and disadvantages experienced by children of these intercultural marriages. Four individualized 
responses of significance to this study follow. The ability to look at their primary culture clearer was cited as an advantage. Disadvantages included: reverse-ethnocentrism on the part of the non-U.S. parents; being different and conscious of it; and feeling as thought they have to choose between the two sides. Responses which were supported by two or more subjects follow. A feeling of displacement due to having no concrete background was mentioned by $29 \%$. Being raised monolingually was cited a disadvantage by 298 . The final disadvantage indicated was that of conflict within the family due to value differences, supported by $57 \%$ of those interviewed.

Along the lines of advantages, $29 \%$ cited exposure to different foods; learning to both question and compromise was discussed by $29 \%$; and a further $29 \%$ represented responses indicating an increased flexibility, adaptability and or openmindedness. Forty-three percent stated that exposure to a different language was indeed an advantage. An increased sensitivity to others and differences was cited by $43 \%$ of the population. And finally, $43 \%$ disclosed that an advantage of having parents from different countries was that it provided the child with more choices or options for their life, from which one could pick and choose, blending the best of both if one desired.

The first three questions in section II explore communicative behaviors as reported by the children of intercultural marriages. Of the children interviewed, $86 \%$ 
reported having discussed the parents coming from different countries with their parents. This issue was also discussed with their siblings by $57 \%$. Of the above $86 \%, 50 \%$ revealed that they discuss this issue predominantly with the U.S. parent. $16 \%$ stated that the non-U.S. parent is the focus of these discussions. Only one of the seven children reported discussing this issue with a friend. The friend was stated to also be a child of intercultural marriage.

Forty-three percent mentioned the parents having discussed differences in schooling. In response to question 18, $71 \%$ disclosed that parents discussed differences in their upbringings and childhoods as was relevant to the childrens life experiences.

The final open-ended question on communicative behaviors generated several individualized responses including the advantages of extended family and language; and disadvantages such as lack of religious education. Five of the seven subjects stated that their parents had never directly discussed with them advantages or disadvantages of having parents from two different countries.

The interviews ended with an open-ended question encouraging participants to add any information or comments regarding their experiences as children of intercultural marriage. Once again, many individualized responses of interest resulted. Following are examples: "Don't marry interculturally" (Y-AM); "I always thought it was really neat" (I-AF); "If my parents had not discussed the 
differences with me, I would be oblivious as to my identity" (D-AM); "Dad would like us to have more of a bicultural ldentity than we do. He works hard for his ideals... I don't know if he sees his effort succeed in us" (H-AM); "Children bring out the differences. The longer you are married the more difficult it becomes" ( $Y-A F)$.

\section{CHILDREN'S INTERVIEW DISCUSSION}

\section{Overview}

The following paragraphs provide an overview and discussion of results based on the categories of analysis outlined in chapter III.

That $71 \%$ of the children reported discussing cultural difference with their parents is supportive of results from the preliminary surveys indicating that parents with children 13 years of age and older discuss cultural differences with their children more often than parents with younger offspring.

Interestingly, 50\% revealed that discussion occurs predominantly with the U.S. parent. As indicated in the results, a high percentage of the children identified themselves as full Americans, as opposed to a hybrid. These children appear to identify themselves more with the U.S. parent, as is indicated in the following quote: "It is difficult for father to understand us and our mother" ( $Y$ AF). Considering the minimal amount of time spent in the non-U.S. parent's culture by children interviewed, that they 
identify closer with the U.S. parent is not surprising. However, the communicative behavior reported could be seen as encouraging a "we" - "them" attitude within the family which is viewed in the literature as counterproductive to the development of increased intercultural sensitivity.

In response to the final research question, results revealed a consistency among reports of awareness by the children and their parents. Of the sixteen issues reported by the children interviewed, $69 \%$ were consistent with those reported by the parents. Upon breakdown into the categories of analysis, category I rated a $62.5 \%$ consistency, and Category III a $100 \%$ consistency. Results also show that implications of biculturalism are rarely discussed among families of intercultural marriage. The two children who reported discussing issues, listed solely advantages of being raised in an environment with parents from two different cultures, validating findings from the first interview phase. Considering reports that implications are rarely discussed among families of intercultural marriage, it is surprising to find such a high percentage of consistency in awareness of the issues. The nature of responses found in the results section is supportive of a high rate of exposure to cultural differences which could explain the high rate of consistency found.

The nature of the chlldren's responses defining biculturalism is supportive of results from the parents interviews. Findings show that the parents and children's 
understanding of the term "biculturalism" is highly similar, as well as uniform with Ikeda's (1982) and Harper's (1986) discussions in Chapter I. One interesting note is that the children also repeatedly stressed the importance of bilingualism in being bicultural, as was found in interviews with the parents.

\section{Categories}

According to the four categories of analysis, the following themes found salient in results from the children's interviews are listed below and then discussed.

Category II: Advantageous Implications - more and broader perspectives; bilingualism; international awareness; greater awareness, recognition and acceptance of cultural differences; sensitivity and awareness of ethnocentrism; greater sensitivity and acceptance of new ideas and behaviors. Problematic Implications - culture conflict.

Category I presents $41 \%$ of the themes found in the literature review. Two advantageous implications listed in Category I I were described by interviewees as "feeling freer from ethnocentric and prejudicial attitudes"; and "being more open-minded", including a realization that ones' behavior needs to change depending on the environment: "You have to change your behavior when you go there and deal with those people" (I-AF). An awareness and understanding of differences in behaviors was noted by $86 \%$.

Included in problematic implications is culture conflict. As described by Tseng et. al. (1977) in Chapter 
II, culture conflict includes a dual identification which can lead to confusions and/or feelings of divided loyalty. In addition to reports of confusion due to the two cultures cancelling out one another, one subject revealed a disadvantage as feeling as though they had to choose between the two sides.

Category III: Advantageous Implications - exposure to different foods; travel and interest in other cultures; ability to question home cultural values. Problematic Implications - monolingualism; the inability to truly understand the foreign culture.

Category III is composed of flve themes which were generated in the preliminary surveys. All five themes were also validated by results from the children's interviews. Two results are coded as extensions of the second advantageous theme, "an increased opportunity and interest in travel abroad". They also felt that extended family abroad was a plus. Furthermore, $50 \%$ indicated experiencing a strong interest in other cultures. The ability to question and examine more closely different points of view, or differences in general is seen by the researcher as an extension of the theme, "learning to question home cultural values".

One last theme consistently reported was "the inability to truly understand the foreign culture". specific indications of this can be seen in the following quote: for example, having those roots that go back to 
Europe, but also being distant from those. And that distance is real clear ... it irritates. (D-AM)

This feeling of displacement revealed an inability to totally identify with the non-U.s. culture, yet feeling attached to it which was stated as a definite disadvantage.

Category IV: Advantageous Implications - uniqueness; more choice and options; and the ability to compromise. Problematic Implications - conflict within the family. Category IV represents salient new themes generated in the final interview phase. All themes in this category were reported by $50 \%$ or more of the interviewees. Two of these advantageous issues represent qualities which are valued highly in the U.S.. "Uniqueness" and "more choice and options" are both basic values within American society. As was previously discussed, the children in this study reported little experience in their non-U.S. parent's culture, and overall they consider themselves American versus a hybrid. Therefore, the researcher would assume that the subjects experience life predominantly with a U.S. perspective. In this case, they are more likely to interpret and evaluate their experiences based on American values. Had these children been raised in the non U.S. parent's country, it is highly possible these issues would not have surfaced.

The third advantage generated indicates a more interculturally sensitive perspective. "The ability to compromise" could also lead to, or signal other behaviors 
discussed as advantages in the literature such as: more and broader perspectives; non-judgementality; and a greater sensitivity and acceptance of new ideas and behaviors.

The final issue included in category IV was discussed as problematic. Interviewees revealed that conflict within the family occurred due to value differences, or different expectations of how the children should behave or how to raise the children. This could lead to further problematic implications listed in the literary review as exemplified in the following quote: "When our parents conflict about what is right for us ... sometimes I feel as though I have to choose between the two" $(Y-A F)$. This quote could indicate a "culture conflict" experience. 
CHAPTER V

SUMMARY AND CONCLUSION, LIMITATIONS, AND SUGGESTIONS FOR FURTHER RESEARCH

\section{SUMMARY AND CONCLUSION}

Overall results of the data analysis revealed that couples interviewed demonstrated an awareness of 478 of the issues of biculturalism discussed in the literature. Children reported an awareness of $41 \%$ of those issues discussed in the literature review, listed in chapter II.

Nineteen themes surfaced among the interview subjects. Ten themes are labeled in terms consistent with the literature and are incorporated into the second category of analysis. Five themes not found in the literature surfaced, supported by reports from both the parents and the children. These five themes represent category III. And finally, Category IV consists of an additional four new themes which arose among the seven children interviewed.

As can be seen in Appendix D, advantageous themes found outweigh problematic themes three to one.

In response to the second research question, parents reported that they seldom discuss cultural differences with their children, and only three of the nine couples stated they had verbally discussed advantageous issues with their children. However, results indicated that as the children 
grow older, communication about differences in cultures increases, supported by findings from interviews with parents and children 13 years and older. This is also supported by findings which indicate the majority of couples became aware of issues of biculturalism through their experiences in an intercultural marriage. Interestingly, couples emphasized the importance of exposure to cultural differences over outright verbal communication.

Furthermore, parents disclosed that they discuss advantageous issues of biculturalism with each other more often than problematic issues. Reports also indicated that the couples discuss advantageous but not disadvantageous issues with their children. This finding is consistent with data generated in the childrens interviews, and is demonstrated in the presentation of themes found in Appendix D.

The final research question explored the extent of consistency among reports of awareness by the children and parents. The researcher found a high level of consistency in issues reported by interview subjects.

In general, the findings of this study have been less supportive of the literature than was anticipated. Although reports of awareness of the issues of biculturalism are highly consistent, communicative behavior about those issues was reported as rare. Both parents and children demonstrate an awareness of approximately $44 \%$ of the implications inherent in a bicultural upbringing as discussed in the 
literature. However, the importance of the role of communication as was indicated in Chapter II is not supported by results from this study.

Interestingly, simple exposure to differences as opposed to discussion of them, appears to play a more important role in the awareness levels of these families. This was supported by reports from parents that their experiences raising children led to their awareness, and influenced their emphasis on exposure to differences rather than discussion about differences with their children.

The Iiterature states that both awareness and communication about cultural difference is important in order to achieve intercultural sensitivity. The literature also states that exposure to difference can lead to a lessened ethnocentric stance. In order to deal with issues of biculturalism, results showed that these parents exposed their children to cultural differences rather than actually discussing them. Furthermore, although parents demonstrate an awareness of the advantages of biculturalism, results showed that overwhelmingly, the children have had little exposure to the non-U.S. spouse's native language and limited experience in his or her country of origin.

overall, these results lead the researcher to the following conclusions. The definition of communication being applied has been focused on the verbal communication occurring within these families, rather than nonverbal communication. It could be concluded that the participants 
In this study feel the nonverbal communication within their families is so clear and continuous that it does not need verbal support. However, according to Tseng et. al. (1977) and Rohrlich (1988) verbal communication is fundamental to the development of cultural awareness, successful adjustment to the effects of cultural difference, the ability to use cultural awareness to one's advantage, and overall greater intercultural sensitivity.

Results revealed awareness levels of advantageous implications of biculturalism to be much higher than awareness levels of problematic issues. Results also showed that verbal discussion about differences and implications of blculturalism is rare and considered relatively unimportant by these parents. Furthermore, parents disclosed that they never discuss problematic issues with their children. And finally, when asked about differences in their cultural backgrounds which had led to conflict regarding raising their children, $100 \%$ of couples interviewed responded "none" or passed on the question.

There are several possible reasons for the report of no conflict. Perhaps it is human nature to ignore issues which make us uncomfortable, therefore the issue was avolded in the interview. It is also possible that participants were reluctant to reveal personal issues to the interviewer which dealt with conflict. However, it could be concluded that these families actually do avoid in their relationships, discussion of cultural issues that might lead to outright 
conflict. A cultural factor in avolding the toplc of difference might be that non-U.S. spouses could perceive discussion of such issues as taboo, or unnecessary, depending on their cultural perspectives and values. It is also conceivable that they are unconsciously behaving according to American norms. This would be highly likely based on the amount of time spent in the U.S. by non-U.S. spouses.

Another cultural factor may be the American tendency to employ win-lose strategies in conflict situations. In general, Americans enter a discussion of this nature with the expectation that both people involved want to win. A win-lose situation generally indicates a resolution involving one "reality" or "truth". This outcome is usually attained by a "one-way adjustment", where one partner willingly accepts the others' reality. This researcher proposes that this indicates a more ethnocentric position than willingness to enter discussions of this nature with the expectation of a win-win outcome. A win-win would indicate an agreement that there are two or more viable realities existing simultaneously. Resolution would be a deeper understanding of one anothers' positions, rather than attaining a common position. Perhaps these couples employ the win-lose strategy, indicated by avoidance of a discussion which they may not win. 
LIMITATIONS OF THE STUDY

As is true with most qualitative studies, there are some limitations to this preliminary investigation. According to Taylor and Bogdan (1984), the qualitative researcher should pay close attention to the population used in the study. This study was a preliminary investigation which in following the concepts of theoretical sampling, focused on the potential of each family to contribute to the study, rather than the number of families studied. The study was restricted to qualifying families in the greater Portland Metropolitan area. The researcher utilized the "snowballing" technique during a six month period to obtain the ten participating families. Due to the type of study and the necessary selection procedure, it would be unreliable to generallze results found to a larger population.

Qualitative researchers should also be aware of the level of subjectlvity in the interpretive phase of data analysis. The humanistic nature of qualitative research calls on researchers to use their own theoretical knowledge and assumptions to interpret their data. Taylor et. al. (1984) states: "... the best check on the researcher's bias is critical self-reflection" (p. 142). This researcher is a partner of intercultural marriage, as well as a new parent. Her motivation in exploring this topic is to apply the theoretical knowledge acquired towards raising her child within a family of intercultural marriage to be 
interculturally sensitive. The researcher began this study with the assumption that by beginning the educational effort to increase intercultural sensitivity during a child's formative years, a parent may offer alternatives to the traditional ethnocentric positions outlined in Bennett's (1986) model. This motivation may have inclined the researcher to focus on issues related to her interests, drawing attention away from the specified research questions. Thus the previous assumptions and interests held by the researcher may have detracted from the collection of additional data relevant to this study.

The researcher's effect on the interview phase is also of significance. This researcher feels that being a member of a family of intercultural marriage made her more sensitive towards the participants. However, it is possible that the interviewees assumed she knew or understood their experiences based on this information, and therefore did not explain or respond to questions as completely. Another possibility is that because the researcher is in the same situation, interviewees focused more on positive rather than negative experiences. This could have influenced the outcome of the study. The relationship which developed between the researcher and the interviewees helped establish a more comfortable environment in which the interviewees shared personal experiences, opinions and thoughts. Another limitation to be considered was that couples were interviewed together, as were co-participating 
siblings. The influence of reports from participants could have limited responses from their partner or sibling. The researcher noted that each of the spouses remained passlve to at least one question during the interview, either by nodding the head in agreement, or responding that they agreed with the spouse or sibling. Had the researcher interviewed participants separately, she could have collected more information. This researcher felt that as the focus of this study was on their experlences as a member of an intercultural family, a joint interview would create a more comfortable and supportive atmosphere. The researcher found that both the couples and siblings interviewed together were open, often disagreeing with each other and adding different opinions and perspectives.

The researcher also found minor limitations in Interview schedule $I$ as a research tool. As mentioned in Chapter IV, questions 9 and 10 did not generate comments relevant to this study. The researcher would suggest that question nine be deleted from the interview schedule altogether, and question 10 worded differently in order to obtain the information looked for. For instance "what Issues/differences have you found that you've had to deal with more than once?" Following the analysis of the data, the researcher noted two follow-up questions which could have clarified information generated. The first should be added to Interview Schedule I following question 26. "When discussing the positive aspects you have listed, were they 
discussed as advantages in general, or as advantages of having parents from different countries?" And one final question would be added to explore whether the parents with children 13 years of age and older discuss cultural differences more than other issues, or whether the increase is a part of normal increased communication as children grow older.

\section{SUGGESTIONS FOR FURTHER RESEARCH}

This study focused on intercultural families' awareness levels of the issues inherent in a bicultural upbringing according to the literature. Although data collected showed a consistency in awareness of advantageous issues, this study did not explore whether participants use this knowledge to their advantage.

Additional questions could now be addressed. This study focused on families of intercultural marriage as the literature suggests children of these marriages have learned to deal with cultural differences. It would be of interest to explore which stages of Bennett's (1986) model of intercultural sensitivity this population falls into. In terms of intercultural sensitivity, the literature considers it fundamental for parents and their children to verbally discuss their experiences and awareness of cultural differences. Even though the variables of exposure to and awareness of difference are significant, they do not 
indicate that these families show increased intercultural sensitivity.

Do these families demonstrate a higher level of cultural awareness than monocultural families? As noted earlier, people are increasingly experlencing contact with those from other cultures, either in the workplace, at school, or within their neighborhoods. The literature does not discuss the effect this had on the monocultural family within our society.

How does the interaction within a family of intercultural marriage affect the cognitive processes of the children? Children need to be made aware of cognitive processes, conscious that they're setting their own boundaries, forming what exists or does not exist. If a child learns to construe the world through a thinking or cognitive mode, this could lead to the development of the abllity to consciously extend his boundaries, whereas if the child approaches the world through a feeling mode, he may only be able to extend his boundaries unconsciously.

Why are some of these children able to take on a multicultural, rather than a bicultural perspective? In a bicultural position, a child is aware that there are two different ways to construe reality, but could end up in the dualistic position where the "truth" is that there are two realities. The multicultural position enables them to be aware of their own creation of perspective, thus allowing cultures to be choices rather than inevitabilities. 
specific research needs to be done in order to explore the variables which lead children of intercultural families to develop a more interculturaliy sensitive multicultural perspective.

It is this author's contention that waiting to introduce intercultural concepts and skilis to children once they have internalized a primary world view slows down the developmental process and reinforces ethnocentric attitudes. Beginning the educational effort to increase intercultural sensitivity during the child's formative years may offer alternatives to the traditional ethnocentric positions outlined in Bennett's (1986) model. This researcher proposes that socialization in an environment of intercultural marriage offers characteristics which can supply a child with an ethnorelativistic assumptive base rather than an ethnocentric one. 


\section{REFERENCES}

Barna, L. M. (1988). Stumbling blocks in intercultural communication. In Samovar, L.A. and Porter, R.E. (Eds). Intercultural communication: A reader. Belmont, California: Wadsworth, Inc.

Bennett, J. J. (1986). Towards ethnorelativism: A developmental model in intercultural sensitivity. In Paige, M., (Ed). Cross-cultural orientation. New York: University Press of America.

Berger, P. and Luckmann, T. (1967). The social construction of reality. Garden City, New York: Doubleday and Company, Inc.

Bodger, C. (1984). The challenges of cross-cultural marriage. Glamour, May, pp. 314 - 319.

Bossard, J. H. and Boll, E. S. (1957). One-marriage - two faiths. New York: The Ronald Press Company.

Bruteau, B. (1979). The psychic grid. Wheaton, Illinois: The Theosophical Publishing House.

Christian, C. (1985). The acculturation of the bilingual child. Bilingualism and the bilingual child. New York: Anno Press.

Condon, J. C. and Yousef, F. (1979). An introduction to intercultural communication. New York:

Bobbs-Merrill Co., Inc.

Dooley, D. (1984). Social research methods. New Jersey: Prentice-Hall Inc.

Elkin, F. (1960). The child and society. New York: Random House.

Erzen-Toyoshima, M. (1986). An exploration of cultural differences in Japanese-American intercultural marriages. Portland state university: unpublished Masters Thesis.

Gordon, A., I. (1964). Intermarriage. Boston: Beacon Press. 
Harper, S. J. (1986). A comparison of theory and life experiences in heteroculturality. Portland state University: Unpublished Masters Thesis.

Henriques, F. (1974). Children of conflict: A study of interracial sex and marriage. New York: Dutton.

Ho, M. K. (1984). Building a successful intermarriage between religions, social classes, ethnic groups, or races. St. Meinrad, Indiana: Abbey press.

Hoopes, D. (1981). Intercultural communication concepts and the psychology of intercultural experience. In Pusch, M. D. (Ed)., Multicultural education: A crosscultural training approach. Chicago, Illinois: Intercultural press, Inc.

Ikeda, K. (1985). A descriptive study of the relationship between cultural sensitivity in the acculturation process and the second language learning process. Portland State University: Unpublished Masters Thesis.

Johnson, R. C and Nagoshi, C. T. (1986). The adjustment of offspring of within-group and interracial intercultural marriages: A comparison of personality factor scores. Journal of Marriage and the Family, 48 , pp. $279-284$.

Kant, C. S. (1985). The realities of aging. Boston, Mass: Allyn and Bacon, Inc.

Kelly, G. (1963). A theory of personality. New York: WW Norton and Company.

Lambert, W. E. (1967). A social psychology of bilingualism. Journal of Social Issues, 23, pp. 91 - 109.

Lum, J. (1982). Marginality and multiculturalism: Another look at bilingual/bicultural education. In Samovar, L. A. and Porter, R. E., (Eds), Intercultural communication: A reader, pp. 384 - 388. Belmont, California: Wadsworth.

Park, R. E. (1928). Human migration and the marginal man. American Journal of Sociology, 33, pp. $881-893$.

Paulston, Christina Bratt. (1978). Biculturalism: some reflections and speculations. Tesol Quarterly, vol. $12,4, \mathrm{pp} .369-380$. 
Porter, R.E. and Samovar, L. A. (1988). Approaching intercultural communication. In Samovar, L.A. and Porter, R. E. (Eds.) Intercultural communication: A reader. Belmont, California: wadsworth, Inc.

Rohrlich, B. F. (1988). Dual-culture marriage and communication. International Journal of Intercultural Relations, Vol. 12, pp. $35-44$.

Shibutani, T. (1961). Society and personality. Englewood, New Jersey: Prentice-Hall, Inc..

Sigel, I. E. (1977). Cognitive development from childhood to adolescence: A constructivist perspective. New York: Holt, RInehart, and winston.

stonequist, E. V. (1935). The problem of the marginal man. The American Journal of Sociology, 41, pp. $1-12$.

Taft, R. (1981). The role and personality of the mediator. In S. Bochner (Ed), The mediating person: Bridges between cultures, Cambridge, Mass: Schenkman.

Taylor, S. J. and Bogdan, R. (1984). Introduction to qualitative research methods. New York: John wiley and sons.

Tseng, w., Mcdermott, M., and Maretzki, L. (1977). Adjustment in intercultural marriage. Honolulu, Hawali: The University of Hawaii Press.

Tucker, R., Weaver, R. L., and Berryman-Fink, C. (1981). Research in speech communication. Englewood Cliffs, New Jersey: Prentice-Hall, Inc.

United States Commission on Civil Rights. (1975). A better chance to learn: Bilingual-bicultural education. Clearinghouse Publication, No. 51, May.

Werner, E. E. (1979). Cross-cultural child development. Monterey, California: Brooks/Cole Publishing Company.

Whorf, B. L. (1956). Language, thought and reality. Cambridge, Mass: Wiley.

Yogev, A., Jamshy, and Hara. (1983). Children of ethnic intermarriage in Israeli schools: Are they marginal? Journal of Marriage and the Family, vol. 45, No. 4, pp. $965-973$. 


\section{APPENDIX A}

\section{PRELIMINARY THEMATIC ANALYSIS OF THE LITERATURE}

\section{Advantageous Implications}

Non-judgementality

More and broader perspectives

Sensitivity and awareness of ethnocentrism

International awareness

Greater awareness, recognition and acceptance of cultural difference

More open and receptive about self and others

Greater sensitivity and acceptance of new ideas and behaviors

Bilingualism

Problematic Implications

Culture conflict

Partial assimilation of both cultures

Marginality

Loneliness

Identity confusion

Detachment, indifference

Indecisiveness

Negative self-concept

Increased self-consclousness and sensitivity 


\section{APPENDIX B}

\section{PRELIMINARY SURVEY}

Please answer the following questions by circling the most appropriate response. Feel free to discuss the questions with your spouse, or with your children. On questions $4 \mathrm{~b}$ and 5b, list as many examples as you can think of. Use the back of this page, or attach a separate plece of paper.

1. How often do you discuss with each other, differences in your cultural backgrounds as they might affect your children?

5

more than once once a a week week
3

once a
week
2

seldom

never

2. How often do you discuss these differences with your children?

5

more than once a week
4

once a week
3
once a week

2 1

seldom

never

3. How important do you think differences in your cultural backgrounds are in the process of childrearing?

5

very important
4

3

2

1

not at all

important 
4A. How often do you and your spouse discuss the negative aspects of raising children in an environment with parents from two different cultures?

5

4

3

2

1

more than once once a a week

week

once a month

seldom never

4B. What are some of the negative aspects you discuss?

5A. How often do you and your spouse discuss the positive aspects of ralsing children in an environment with parents from two different cultures?

5

4 3 2 1

more than once a week once a week once a month

seldom never

5B. What are some of the positive aspects you discuss? 


\section{APPENDIX C}

\section{THEMATIC ANALYSIS OF THE PRELIMINARY SURVEY}

\section{Problematic Implications}

Child unable to understand the 'foreign culture'

Identity problems

Monolingualism

\section{Advantageous Implications}

Tolerance of prefudice and ethnocentrism

Exposure/tolerance of different foods

Learns to questions established home cultural values

Broadened horizons

International awareness

Bilingualism

Greater sensitivity and understanding of different people Travel opportunities 


\begin{abstract}
APRENDIX D
THEMES FROM THE LITERATURE AND PRELIMINARY SURVEYS
\end{abstract}

\title{
CATEGORY I
}

Advantageous Implications

Sensitivity and awareness of ethnocentrism Open and receptive about self and others Greater sensitivity and acceptance of new ideas/behaviors

Problematic Implications

Culture conflict

Partial assimilation of both cultures Marginality

Loneliness

Detachment

Indecis iveness

Negative self-concept

Increased sensitivity

\section{CATEGORY I I}

Advantageous Implications

Non-judgementality

Broader and more perspectives

International awareness

Bilingualism

Greater awareness, recognition and acceptance of cultural differences

Problematic Implications

Identity confusion

\section{CATEGORY III}

Advantageous Implications

Exposure to a varlety of foods

Increased opportunity and interest in travel abroad Learning to question home cultural values 


\section{Problematic Implications}

Monol ingualism

Inability to truly understand the 'foreign culture' 


\section{APPENDIX E}

\section{PARENTS' INTERVIEW SCHEDULE}

If you feel any question is unclear, please tell me so I can clarify it for you. If any question feels too personal, please let me know. Feel free to pass on any question which makes you feel uncomfortable.

\section{Demographics and Experience}

subjects :

Number of Years Married:

Husband's/Wife's Ethnicity:

Children and Ages:

Place of Birth:

Number of Years in Primary Culture:

\section{SECTION I}

1. Do you have any knowledge of the language of your spouse's country? speak Read Write

2. What contact have you had with people from your spouse's country?

Time spent in country of spouse

$A M$ other

3. How familiar are you with the social norms of your spouse's country?

Examples:

Holidays : 
Customs :

4. Do you practice any of these norms, holidays, customs in your household? Which ones?

5. Do you consider yourselves bicultural?

6. Do you consider your children bicultural?

7. How would you define biculturalism?

SECTION II - Part A

8. What are some examples of the differences you discuss with each other as they might affect your children? (If none, skip to \#18).

9. What differences in your cultural backgrounds have led to conflict regarding ralsing your chlldren?

10. If you solved these issues before you had children, once you put your ldeas regarding how to raise them into practlce, did you find that you still had to deal with the same issues again? If so, which ones?

11. Were you aware of the negative and/or positive aspects you mentioned in the survey, prior to having children? or did you learn through experience?

Did you discuss these differences at that time? Any decisions or resolutions made?

12. How did you attempt to overcome the negative aspects that you felt your children might experience?

13. How did you ensure that your chlldren would benefit from positive aspects of having parents from two different cultures? 
14. How was your prior awareness and/or communication about the negative and/or positive aspects advantageous for your children?

Has it helped you in the process of raising your children? 15. Which negative and/or positive aspects of being raised with parents from two different countries do you think your children experlence?

16. How aware do you think your children are of the negative aspects you have mentioned?

5

Very aware
43
2

Not at all

17. How aware do you think your children are of the positive aspects you have mentioned?

5

Very aware
$4 \quad 3$

1

Not at all

aware

\section{PART B}

18. If you feel that no cultural difference exists, is it because you have already discussed or solved any issues that my have arisen? (If differences discussed, ask \#10, otherwise continue with \#19).

If so, what issues? What were the solutions?

19. Considering that you are both from different countries and backgrounds, why do you think you have not experienced any significant differences? (If differences not discussed, proceed to \#23 and \#28) 
20. How Important do you think it is that your chlldren are aware of different cultures, customs, ways of life?

$\begin{array}{lllll}5 & 4 & 3 & 2 & 1\end{array}$

Very important

Not at all Important

21. How Important do you think it is that your children are aware that you are from different countries?

$\begin{array}{lllll}5 & 4 & 3 & 2 & 1\end{array}$

Very Important

Not at all

important

\section{SECTION III - Communicative Behaviors}

22. How important do you think it is that your children not only experlence these differences, but are aware and able to talk about them with you or with others.

$\begin{array}{lllll}5 & 4 & 3 & 2 & 1\end{array}$

Very Important

Not at all

Important

23. What do you think reasons are for discussing or not discussing these differences between you with your children? 24. Which, if any, of the differences in your lifestyles, childhood, or beliefs, have you discussed with your children?

25. What are some examples of the differences you discuss with your children?

26. Which positive and negative aspects that you have listed, have you discussed with your children? Do you intend to discuss with your children? 
27. How do you plan on discussing these issues with them as they grow older?

28. If you do not discuss differences with your children, how do you think they will become, or became aware of different cultures, foods, customs?

\section{OTHER}

29. Is there anything else you would like to add? 


\section{APPENDIX F}

\section{CHILDREN'S INTERVIEW SCHEDULE}

\section{Demographics and Experlence}

\section{Age :}

Mother's Ethnicity:

Father's Ethnicity:

Brothers/sisters? Ages?

\section{SECTION I}

1. What languages did you speak growing up?

2. Can you carry on a conversation in each language?

Read Write Is it a struggle for you?

Do you think in each language, or do you have to translate?

3. How much time have you spent in each of your parent's countries? Mother's Father's

\section{SECTION II}

4. What do you like about having parents from different countries?

5. What do you dislike about having parents from different countries? 
6. When you think about Americans or people from your parents' countries, do you feel like you belong, are a part of both groups? Do you identify with both groups?

7. Do you consider yourself bicultural?

Do you consider your parents bicultural? AM Non U.S.

8. How would you define biculturalism?

9. Would you characterize yourself as all American, or do you feel you are a -American?

10. Do your friends tend to be from a specific ethnic or cultural group? Are they all Americans? What is the ethnicity?

11. Describe specific experiences you have had when you noticed important differences between your parents, due to their being from different countries?

12. Describe any specific experiences you have had when you noticed Important differences between yourself and your friends. Did you feel upset? Does this still bother you? Have you ever discussed this with your parents? Brothers or sisters?

13. What effect has having parents from two different countries had on you?

14. What are the most important things you have learned about other countries/cultures from having parents from different countries?

15. What are some of the advantages in having parents from two different countries? 
16. What are some of the disadvantages in having parents from two different countries?

SECTION III - Communicative Behaviors

17. Have you ever discussed the fact that your parents are from different countries with your parents? Frequency With other family members? Brothers/sisters?

18. What differences in their childhoods/upbringings have your parents discussed with you?

19. What advantages and or disadvantages have your parents discussed with you regarding having parents from two different countries?

OTHER

20. Is there anything else you would like to add? 


\begin{abstract}
APPENDIX G
INFORMATION ON PARTICIPANTS
\end{abstract}

$\begin{array}{ll}\text { HUSBAND } & \text { WIFE } \\ \text { Portuguese } & \text { American }\end{array}$

YEARS IN PRIMARY CULTURE: 20 years all

TIME IN SPOUSE'S CULTURE; 12 years $21 / 2$ weeks

YEARS MARRIED;

$31 / 2$ years

NUMBER OF CHILDREN :

one 3 year old

American Philipino

YEARS IN PRIMARY CULTURE: AII 26 Years

TIME IN SPOUSE'S CULTURE: none 10 Years

YEARS MARRIED:

6 Years

NUMBER OF CHILDREN: Three: 5, 3, and 3 months

Japanese American

YEARS IN PRIMARY CULTURE: 19 years all

TIME IN SPOUSE'S CULTURE:

12 years

6 weeks

YEARS MARRIED :

7 years

NUMBER OF CHILDREN :

one 4 year old

Romanian

30 years

40 years
American

a 11

2 weeks 
YEARS MARRIED:

NUMBER OF CHILDREN :

Indian

17 years

35 years

27 years

YEARS MARRIED:

NUMBER OF CHILDREN :

YEARS IN PRIMARY CULTURE:

TIME IN SPOUSE'S CULTURE:

YEARS IN PRIMARY CULTURE:

TIME IN SPOUSE'S CULTURE:

YEARS MARRIED :

NUMBER OF CHILDREN :

Danish

26 years

21 years

\section{1 years}

Two: 16 and 18 years old

American

Dutch

YEARS IN PRIMARY CULTURE:

TIME IN SPOUSE'S CULTURE:

YEARS MARRIED:

NUMBER OF CHILDREN :
19 years

$21 / 2$ months 27 years

23 years

Two: 17 and 23 years old
American

20 years

YEARS IN PRIMARY CULTURE:

TIME IN SPOUSE'S CULTURE:
20 years

6 years none 
YEARS MARRIED:

NUMBER OF CHILDREN :

YEARS IN PRIMARY CULTURE:

TIME IN SPOUSE'S CULTURE:

YEARS MARRIED:

NUMBER OF CHILDREN :
Hungarian

5 years

one 2 year old

7 years

40 years

10 days

20 years

Three: 16, 15 and 9 years old 


\begin{abstract}
APPENDIX H
INFORMATION ON CHILDREN PARTICIPANTS
\end{abstract}

FATHER' $S$

ETHN I C I TY

SUBJECT 1

American

SUBJECT 2

Dutch

American

Male

18

none

SUBJECT 3

Dutch

American

Female

16

none

SUBJECT 4

Yugoslavian

American

Female

19

3 months

SUBJECT 5

Yugos lavian

American

Male

16

6 weeks

SUBJECT 6

Indian

American

Female

19

10 weeks

SUBJECT 7

Hungarian
American

Male

17

2 years 